"DNA-based nanoscaffolds as vehicles for 5-fluoro-2'-deoxyuridine oligomers in colorectal cancer therapy" Jorge, A.F., Aviñó, A., Pais, A.A.C.C., Eritja, R., Fàbrega, C. Nanoscale, 10(15), 7238-7249 (2018); doi: 10.1039/c7nr08442k

\title{
DNA-based Nanoscaffolds as Vehicles for 5-fluoro-2'-deoxyuridine Oligomers in Colorectal Cancer Therapy
}

\author{
A. F. Jorge,$^{\ddagger a^{*}}$ A. Aviñó, ${ }^{b}$ A. A. C. C. Pais, ${ }^{a}$ R. Eritja, ${ }^{b^{*}}$ and C. Fàbrega ${ }^{\ddagger b^{*}}$
}

${ }^{a}$ Coimbra Chemistry Centre (CQC), Department of Chemistry, University of Coimbra, Rua Larga, 3004-535 Coimbra, Portugal. E-mail: andreiaj@qui.uc.pt. bInstitute for Advanced Chemistry of Catalonia (IQAC-CSIC), J ordi Girona 18-26, E08034 Barcelona, Spain. Networking Center on Bioengineering, Biomaterials and Nanomedicine (CIBER-BBN), J ordi Girona 18-26, E-08034 Barcelona, Spain. E-mail: cgcnqb@cid.csic.es; ramon.eritja@iqac.csic.es.

¥These authors contributed equally to this work.

Abstract. Fluoropyrimidines, such as 5-fluorouracil (5-FU) and related prodrugs are considered one of the most-successful agents in the treatment of colorectal cancer, yet poor specificity and tumor cell resistance remain major limiting bottlenecks. Here, we exploited for the first time the ability of two DNA nanoscaffolds, DNA tetrahedron (Td) and rectangle DNA origami, to incorporate 5-fluoro-2'-deoxyuridine $\left(\mathrm{FdU}_{\mathrm{n}}\right)$ oligomers. In addition, cholesterol moieties were synthetically attached to $\mathrm{Td}$ and DNA origami staples to enhance cellular uptake. DNA nanostructures functionalized with $\mathrm{FdU}_{\mathrm{n}}$ exhibited an enhanced cytotoxicity and higher ability to trigger apoptosis in colorectal cancer cells relative to conventional 5-FU and FdU, especially having cholesterol as internalization helper. The cholesterol content mostly correlates with the increment of the $\mathrm{FdU}_{\mathrm{n}}$ nanostructures cytotoxicity. DNA nanoscaffolds bearing $\mathrm{FdU}_{\mathrm{n}}$ revealed to be able to circumvent 5-FU low sensitivity of colorectal cancer cells. Both DNA nanostructures attained comparable cytotoxic effect yet $\mathrm{Td}$ displays higher antiproliferative action. The ability to reduce the proliferation of cancer cells is mainly related to the concentration of DNA nanostructures. The present work suggests that self-assembled DNA nanoparticles are privileged vehicles for delivering fluoropyrimidines, opening new avenues to the development of promising therapeutics for cancer treatment.

\section{I ntroduction}


5-Fluorouracil (5-FU) has been extensively used in the treatment of diverse severe cancers, including head, neck, breast, gastrointestinal, pancreatic and colorectal cancers. However, the largest impact of this drug has been reported to the treatment of one of the highest leading cause of cancer-related mortality worldwide, colorectal cancer. ${ }^{1,2}$

$5-\mathrm{FU}$ is an equivalent of uracil, in which the hydrogen atom at C5 position is replaced by a fluorine atom, that promptly enters into the cells by means of uracil transport mechanism. ${ }^{3}$ The antitumoral activity of 5-FU is triggered after its intracellular conversion to 5fluoro-2'-deoxyuridine monophosphate (FdUMP), 5-fluoro-2'deoxyuridine triphosphate (FdUTP) and 5-fluorouridine triphosphate (FUTP), and all these three active metabolites interfere in critical cellular processes. FdUMP binds covalently to the nucleotide-binding site of thymidylate synthase (TS) and forms a stable ternary complex with a reduced folate co-factor. ${ }^{4-6}$ In this way, deoxythymidine monophosphate (dTMP) synthesis is inhibited and "thymineless cell death" takes place. ${ }^{7,8}$ While FdUTP is misincorporated to DNA and, consequently, increases the frequency of base excision repair (BER) events, which culminates in DNA strands break and cell death. ${ }^{9}$ Finally, FUTP is incorporated in RNA, leading to the impairment of the normal RNA processing and function. ${ }^{10-14}$

5-FU cell resistance is described as one of the major problems in clinical practice, since cancer cells can become immune to this drug mainly by increasing the rate of dTMP biosynthesis ${ }^{15}$ or by increasing 5-FU catabolism promoted by dihydropyrimidine dehydrogenase (DPD), ${ }^{16}$ although other mechanisms of resistance are recognized. ${ }^{17}$ As a consequence, these factors largely contribute to the reduction of 5FU bioavailability. In addition, the lack of specificity for cancer cells provokes adverse side effects, as toxicity on the gastrointestinal tract and hematological, neural, dermatological and cardiac dysfunctions, ${ }^{18,}$ 19 thus discouraging the use of $5-\mathrm{FU}$.

Important modulation strategies have been developed to the enhancement of the inhibition of TS activity, residing mainly in the synthesis of 5-FU analogs resistant to oral administration, such as capecitabine, $^{20,21}$ tegafur-uracil ${ }^{22}$ and S-1. ${ }^{23,24}$ Such prodrugs are based on the metabolic conversion to 5-FU as their primary mechanism of cytotoxicity. Another important contribution to improve 5-FU efficiency is its combination with other active compounds, such as folinic acid, leucovorin, irinotecan and oxaliplatin, which enhances synergistically the anticancer response. ${ }^{25-27}$ In a different approach, the antitumoral action of the decamer $\mathrm{FdU}_{10}$ composed by ten units of FdU was widely studied by Gmeiner and co-workers. ${ }^{28,}{ }^{29}$ FdU $_{10}$ has shown to be highly more effective than 5-FU in leukemia, glioblastoma 
and colon cancer treatment, involving dual-targeting of TS and DNA Topoisomerase I (Topl). ${ }^{30}$

Currently, 5-FU analogs combined with some of the abovementioned promoters of therapeutic efficiency are employed clinically but, nevertheless, the urgent need of novel drug nanocarriers capable of reducing cytotoxicity by sparing healthy cells, augmenting drug bioavailability and enhancing drug delivery into target cells is recognized. ${ }^{31}$ In the last two decades, the biocompatible selfassembled DNA nanostructures stood out as effective drug carriers. ${ }^{32}$, ${ }^{33} \mathrm{~S}$. N. Seeman set the bases for the tile assembly method used to synthesize two-dimensional periodic lattices. ${ }^{34} A$ wide range of $2 D$ and 3D geometrical structures were designed including polyhedral forms, as cube, $^{35}$ octahedron, ${ }^{36}$ tetrahedron, ${ }^{37}$ dodecahedron, ${ }^{38}$ among others, $^{39}$ normally with diameter size in the range of $20-50 \mathrm{~nm}^{40-42}$ Another significant breakthrough in the DNA nanostructures field was the development of DNA origami by $P$. Rothemund, ${ }^{43}$ where a long, single-stranded scaffold is folded with the help of hundreds of short 'staples' strands to create 2D and 3D shape. Since then, various DNA motifs have been designed comprising diameter size in the range of 100-200 nm. ${ }^{42}$ These DNA templates allow a programmable design not only in terms of structural size and shape but also in the precise location of multi-functional components intercalated or attached to their surface. ${ }^{44,45}$

One of the most promising drug nanocarriers is the tetrahedral DNA nanostructure (Td), developed by Turberfield and co-workers ${ }^{37,46}$ in which four short complementary DNA strands hybridize in a single step process. This versatile structure has been successfully used to deliver anticancer drugs, as doxorubicin hydrochloride (DOX) and therapeutic nucleic acids. ${ }^{33,47-49}$ In addition, it was observed that DNA Td structures are readily internalized into mammalian cells without transfection agents and they are resistant in the intra- and extracellularly domains for a relatively long period of time. ${ }^{50,} 51$ Likewise, DNA origami technology has allowed developing different nanostructures which prove to be easily internalized and stable in living systems. ${ }^{52-54}$ DNA origami was used as a carrier for the delivery of DOX in MCF-7 to circumvent cell resistance and to increase drug concentration in tumor. ${ }^{55,56}$ Also, cytosine-phosphate-guanosine $(\mathrm{CpG})$ oligonucleotides were successfully incorporated in a DNA origami tube to trigger immune response. ${ }^{57}$

In the present work, we inspected for the first time the ability of DNA nanostructures to deliver $\mathrm{FdU}_{\mathrm{n}}$ oligonucleotides into colorectal cancer cells. To pursue this goal, two classic forms of DNA nanostructures, a DNA Td and a rectangle DNA origami, were investigated and compared in terms of cell uptake and cytotoxic effects. The process of 
DNA nanoscaffolds construction encompassed the incorporation of chemically modified staples, following two strategic approaches. Firstly, oligonucleotides composed by a number of FdU nucleotides $\left(\mathrm{FdU}_{\mathrm{n}}\right.$ ), with $\mathrm{n}$ corresponding to the number of monomers (5-fluoro-2'deoxyuridine units, FdU) were inserted in the 3 '-end of inherent $\mathrm{Td}$ and origami staples, to act as therapeutic agents. Secondly, selected staples were functionalized with hydrophobic cholesterol moieties to inspect the effect of this component as promoter for nanocarrier uptake. The rational design of the modifications inserted in the DNA nanostructures was made to maximize the number of the novel synthesized strands without disrupting their 3D dimensional structures.

\section{Results and discussion}

Characterization of the DNA nanoscaffolds. To investigate the suitability of the two selected DNA templates as delivery systems, we modified the sequences of standard staples by adding $\mathrm{FdU}_{\mathrm{n}}(\mathrm{n}=10$ to 14$)$ at $3^{\prime}$-end of single-stranded oligonucleotides and cholesterol at $5^{\prime}$-end. Figures $1 \mathrm{~A}$ and $2 \mathrm{~A}$ represent schematically the presumed positioning of all attached functional moieties inserted in the Td and rectangle DNA origami tridimensional surface, respectively. Staples used for nanostructures engineering are listed in Table 1. The sequences and characterization of standard and new oligonucleotides used in the formation of both DNA-based nanostructures are given in supplementary Tables S1, S2 and S3. Tetrahedral DNA nanostructures constituted by 20 base pairs (bp) in each edge and rectangle DNA origami were prepared through DNA strands assembling and thermal annealing as reported by Turberfield et $\mathrm{al}^{37}$ and Rothemund et $\mathrm{al}^{43}$ respectively.

The characterization of the nanostructures was carried out using different techniques, such as agarose gel electrophoresis, dynamic light scattering (DLS), atomic force microscopy (AFM) and transmission electronic microscopy (TEM).

For DNA Td, the stepwise addition of staples allows discerning the formation of the Td ( lanes 1-4) (see Figure 1B). The band corresponding to Td (lane 4) shows a distinct shift from the ones corresponding to the mixture of an insufficient number of staples (lane 1-3), demonstrating the correct formation of the tetrahedral structure. The addition of fluorescent dyes, fluorescein and Cy3 in a complementary strand S5, required for flow cytometry and confocal microscopy studies, maintain the migration of nanostructures in the gel (lanes 7 and 8) showing the trend as controls (lane 5 and 6). The addition of the oligonucleotide $\mathrm{FdU}_{10}$ to one of the long $\mathrm{Td}$ staples $\left(\mathrm{S} 1-\mathrm{FdU}_{10}\right)$ (lane 9) does not affect Td formation. For Td-1F-2C (lane 12), Td-1F-3C (lane 13), Td-1F4C (lane 14) and Td-2F-3C (lane 15) assembles, an electrophoretic band was obtained which matches the one belonging to unmodified Td (line 11). 
A

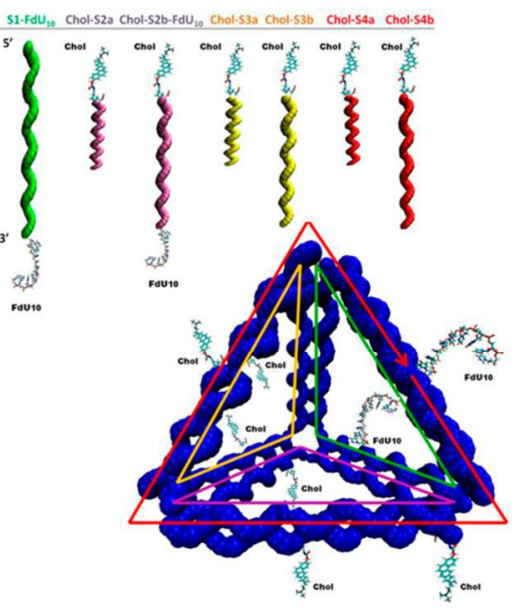

B

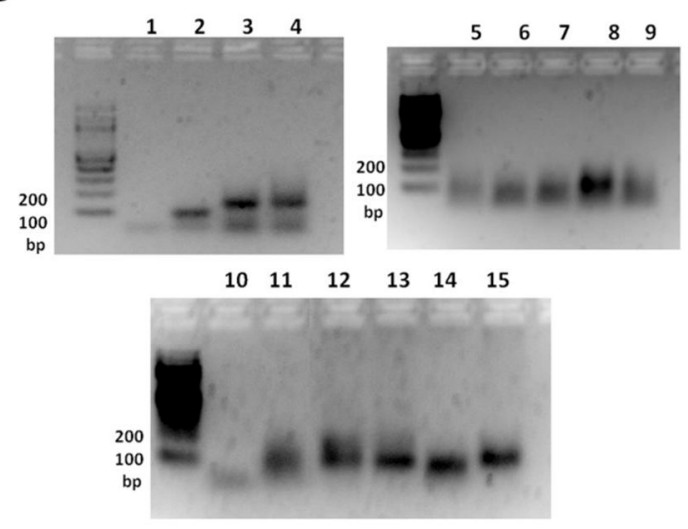

D
C

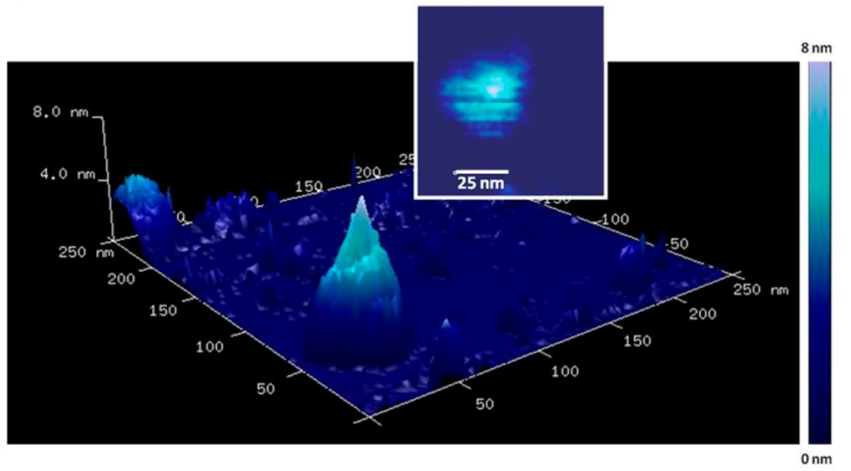

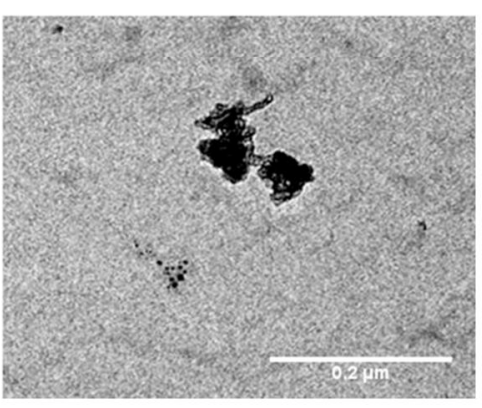

Fig 1. Self-assembly of cholesterol- and $\mathrm{FdU}_{10}$-modified DNA-based Td. A, Schematic representation of relevant modified strands required for $\mathrm{Td}$ assembly and a 3D representation of the presumed site-specific hybridization of cholesterol and $\mathrm{FdU}_{10}$ molecules in the $\mathrm{Td}$ assemble. Cholesterol and $\mathrm{FdU}_{10}$ moieties are detailed at atomistic level while $\mathrm{Td}$ backbone is represented as ribbons. Colour in single-stranded oligonucleotides corresponds to the thin lines delimiting the six edges of $\mathrm{Td}$. B, $2.5 \%$ agarose gels electrophoresis showing the self-assembly of $\mathrm{Td}$, in an increasing order of addition of the DNA strands; (1) S1; (2) S1+S2; (3) S1+S2+S3; (4) Td. The assembling of modified $\mathrm{Td}$ was also monitored by electrophoresis, (5) Td used as control, (6) S1-FdU $10+S 2+S 3+S 4 C$; (7) Td-1F-2C-FITC; (8) Td-1F-2C-Cy3 and (9) Td1F. In third panel shows, (10) S1 and (11) Td used as controls, and the modified Td, (12) Td-1F-2C; (13) Td-2F-3C; (14) Td-1F-4C and (15) Td-1F3C; C, AFM image showing Td in mica surface. Color bar indicates the height of the nanostructures. Inset: AFM 2D image resolving the triangular geometry of $\mathrm{Td}$ vertices. D, TEM image indicating the presence of aggregates for Td-1F4C nanoscaffolds.

Through atomic force microscopy (AFM), the upper edges of an individual tetrahedron reaching the maximum height of $8 \mathrm{~nm}$ (Figure 1C and S3) was visualized, in good agreement with literature. ${ }^{33,46}$ In addition, DNA Td shows a small hydrodynamic diameter of $24.5 \pm 5.8 \mathrm{~nm}$ when analyzed by dynamic light scattering (DLS) (see supplementary Table S4) supporting the value of the diameter found in AFM 2D representation. TEM and DLS were used to assess the effect of modifications in Td structure (Figure 1D and Table 
S4). The structure of $\mathrm{Td}$ with the highest number of cholesterol moieties and concomitantly with the highest size was imaged by TEM, Td-1F-4C, and it exhibits the formation of aggregates including several individual tridimensional structures. DLS shows an increase of a maximum of 8 -fold of Td size when the staples are modified, corroborating the presence of aggregates. As observed, increasing the amount of cholesterol in $\mathrm{Td}$ augments the size of cholesterol aggregates (Table S4).

Table 1 Staples used for engineering DNA tetrahedron and DNA origami.

\begin{tabular}{|c|c|c|c|}
\hline \multicolumn{4}{|l|}{ DNA tetrahedron } \\
\hline Sample & $\mathrm{FdU}_{\mathrm{n}}-$ modified staples & Cholesterol-modified staples & Other Modified staples \\
\hline $\mathrm{Td}-1 \mathrm{~F}$ & $\mathrm{~S} 1-\mathrm{FdU}_{10}$ & - & - \\
\hline Td-1F-2C & $\mathrm{S} 1-\mathrm{FdU}_{10}$ & Chol-S3a, Chol-S4a & $53 b, 54 b$ \\
\hline Td-1F-3C & $\mathrm{S} 1-\mathrm{FdU}_{10}$ & Chol-S2a, Chol-S3a, Chol-S4a & $S 2 b, 53 b, 54 b$ \\
\hline Td-1F-4C & $\mathrm{S} 1-\mathrm{FdU}_{10}$ & Chol-S3a, Chol-S3b, Chol-S4a, Chol-S4b & - \\
\hline Td-2F-3C & $\begin{array}{l}\text { S1-FdU } \\
\text { Chol-S2b-FdU }\end{array}$ & Chol-S2b-FdU ${ }_{10}$, Chol-S3a, Chol-S4a & $52 a, 53 b, 54 b$ \\
\hline $\begin{array}{l}\text { Td-1F-2C- } \\
\text { Cy3/FITC }\end{array}$ & $\mathrm{S} 1-\mathrm{FdU}_{10}$ & Chol-S2a, Chol-S3a & $\begin{array}{l}\text { S2b, S3b, S4c, } \\
\text { S5-Cy3/S5-FITC }\end{array}$ \\
\hline \multicolumn{4}{|l|}{ DNA origami } \\
\hline Sample & $\mathrm{FdU}_{\mathrm{n}}-$ modified staples & Cholesterol-modified staples & \\
\hline Origami- $\mathrm{N}$ & - & - & \\
\hline Origami-4F & $\begin{array}{l}\mathrm{t}-5 \mathrm{r} 4 \mathrm{e}-\mathrm{FdU}_{13}, \quad \mathrm{t}-3 \mathrm{r} 2 \mathrm{f}-\mathrm{FdU}_{14} \\
\mathrm{t} 5 \mathrm{r} 2 \mathrm{f}-\mathrm{FdU}_{14}\end{array}$ & $\mathrm{t} 3 \mathrm{r} 4 \mathrm{e}-\mathrm{FdU}_{14,-}$ & \\
\hline Origami-6F & $\begin{array}{l}\mathrm{t}-5 \mathrm{r} 4 \mathrm{e}-\mathrm{FdU}_{13}, \quad \mathrm{t}-3 \mathrm{r} 2 \mathrm{f}-\mathrm{FdU}_{14} \\
\text { t5r2f-FdU }\end{array}$ & $\mathrm{t} 3 \mathrm{r} 4 \mathrm{e}-\mathrm{FdU}_{14,-}$ & \\
\hline Origami-4F-4C & $\begin{array}{l}t-5 r 4 e-F_{13}, \quad t-3 r 2 f-F d U_{14} \\
t^{5} 2 f-F_{14}, t-3 r 8 e-F d U_{10}, t 3 r 6 f\end{array}$ & $\begin{array}{l}\text { t3r4e-FdU } 14, \text { Chol-t-3r14f, Chol-t-3r18f, Chol-t5r14f, C } \\
\text { f- } \mathrm{FdU}_{10}\end{array}$ & Chol-t5r18f \\
\hline Origami-6F-8C & $\begin{array}{l}t-5 r 4 e-F U_{13}, \quad t-3 r 2 f-F d U_{14} \\
t 5 r 2 f-F d U_{14}, \\
t-3 r 8 e-F d U_{10}, t 3 r 6 f-F d U_{10}\end{array}$ & $\begin{array}{r}\text { t3r4e-FdU }{ }_{14}, \text { Chol-t-3r14f, Chol-t-3r18f, Chol-t5r14f, } \\
\text { Chol-t-1r30f, Chol-t1r22e, Chol-t1r30e }\end{array}$ & Chol-t5r18f, Chol-t-1r22f, \\
\hline
\end{tabular}

As regards modified DNA origami, a unique band is identified in all lanes showing a migration similar to the M13 vector in agarose gel electrophoresis (Figure 2B). The origami 6F-8C (lane 6) exhibited a slight shift in mobility produced by the incorporation of the eight cholesterol moieties. Figures $2 \mathrm{~B}$ and $\mathrm{S} 2 \mathrm{~A}$ demonstrate that the purification process eliminates completely the exceeding staples, and re-suspension in PBS plus $4 \mathrm{mM} \mathrm{MgCl} 2$ does not alter the DNA origami formation. The rectangular morphology of the DNA origami was maintained after the incorporation of extended staples with $\mathrm{FdU}_{\mathrm{n}}$ and cholesterol, as it is shown in the AFM images (Figure 2C and S4, S5). Even after the intercalation of the fluorescent dye SYBRGreen, DNA origami maintained exhibits a unique band with the same migration as standard DNA origami (Figure 2D). Using DLS, a mean value of approximately $120 \mathrm{~nm}$ for standard DNA origami was measured, with a narrow dispersity, as illustrated in Table S4. The incorporation of all modified sequences in DNA origami (Origami-6F-8C) presented a slight increase ca. $20 \mathrm{~nm}$, in the hydrodynamic size. 
A

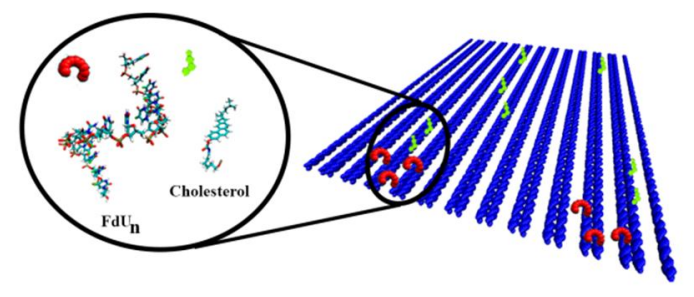

C

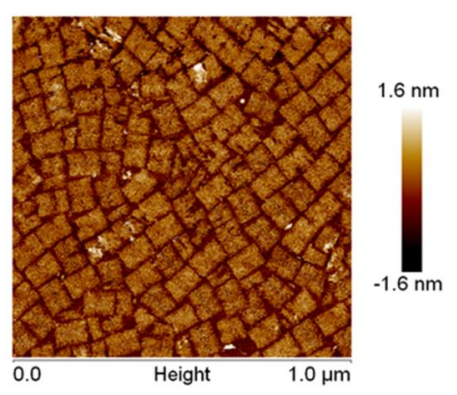

B

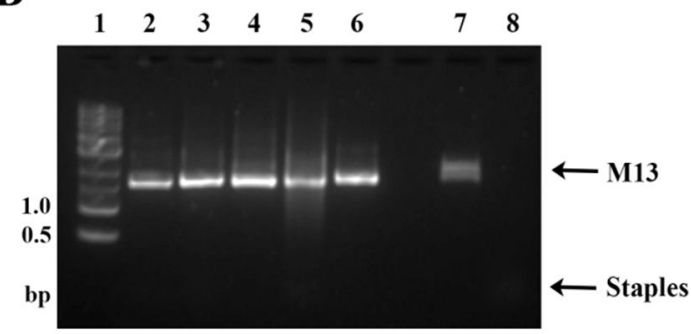

D

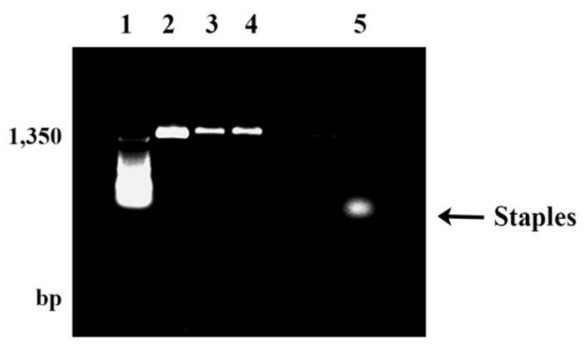

Fig 2. Schematic representation and characterization of the DNA origami. A, Representation of the DNA origami in blue, while the disposition of staples modified with cholesterol and $\mathrm{FdU}_{\mathrm{n}}$ is shown in green and red respectively. The insertion panel shows the cholesterol and $\mathrm{FdU}_{\mathrm{n}}$ chemical structures in sticks color coded by elements. B, $1 \%$ agarose gel electrophoresis of the different purified DNA origami. (1) 1 $\mathrm{kb}$ ladder, (2) DNA origami, (3) DNA origami-4- $F$, (4) DNA origami-4F4C, (5) DNA origami-6F, (6) DNA origami-6-F-8C, (7) M13 scaffold alone and (8) staples C, AFM images of the DNA origami-4F-4C. Image size $1 \mu \mathrm{m} \times 1 \mu \mathrm{m}$ and image height: $-1.6 \mathrm{~nm}$ to $1.6 \mathrm{~nm}$. D, Gel electrophoresis ( $1 \%$ agarose) of the DNA origami stability upon SYBRGreen intercalation. (1) 50 bp ladder, (2) DNA origami (3) DNA origami-4C, (4) DNA origami-8C, (5) staples alone.

Furthermore, the long-term stability of DNA nanoscaffolds in cell culture medium was evaluated by gel electrophoresis. As shown in Figure S1 and S2B, both preserve their 3D structure at least for 24 hours, in agreement with previous works. ${ }^{48,53}$

From these structural characterization we seen that particularly for Td, the modification of staples is more prone to alter the 3D arrangement and therefore the positioning of functional groups is more limited, conversely to what found in DNA origami. The tendency of Td to aggregate in the presence of cholesterol may be related to the evident difference in terms of size/shape of the two nanostructures and also with the distinct working concentrations at which both are characterized.

\section{Anticancer effect of $\mathrm{FdU}_{\mathrm{n}^{-}}$and cholesterol-modified DNA nanoscaffolds}

Cytotoxic and antiproferative activity. Two different colorectal cancer cell lines, HTB-38 and HCC2998, known to possess different levels of sensitivity to 
$5-\mathrm{FU}^{58,59}$ were selected for the inspection of the cytotoxic activity induced by the two DNA nanocarriers with $\mathrm{FdU}_{\mathrm{n}}$. For this, we have conducted MTT (3(4,5-dimethylthiazol-2-yl)-2,5-diphenyltetrazolium bromide), colony formation and apoptosis assays. The MTT experiment was meant to evaluate the cellular metabolic activity of the cells after $48 \mathrm{~h}$ of drug exposure, while the colony assay provides the anti-proliferative action promoted by the nanocarriers, controlling their cellular activity for longer times, generally during 1 or 2 weeks. Apoptosis assay gives information about the mechanism involved in cell death, and is discussed later on.

Firstly, MTT and colony assays were used to study the cytotoxic response of both cell lines promoted by the reference anticancer drugs, 5-FU, 5-fluoro-2'-deoxyuridine ( $\mathrm{FdU}$ ) and the decamer $\mathrm{FdU}_{10}$, at concentrations ranging from $10 \mathrm{nM}$ to $10 \mu \mathrm{M}$, comprising the values of FdU included in DNA nanostructures (Figures S6 and S7). In fact, our study was carried out at concentrations close to those of 5-FU applied clinically. ${ }^{60-62}$ FdU was selected as a control drug since it is considered more efficient in vitro than 5-FU, although its clinical use is non-advantageous because it undergoes a rapid degradation in vivo into the nucleobase 5- FU. ${ }^{62}$ Additionally, $\mathrm{FdU}_{10}$ was used as a control of FdU oligomers mimicking the action expected to the $\mathrm{FdU}_{\mathrm{n}}$ functionalized staples.

Comparing the MTT results obtained for drugs applied in the two cell lines (Figure S6 A and B), it is not possible to distinguish the action of 5-FU and FdU, being both types of cells fairly resistant to these anti-neoplastic drugs. $\mathrm{FdU}_{10}$ oligomers are the most cytotoxic form of deoxynucleoside administration.

In colony assays, 5-FU and FdU have shown to inhibit HTB-38 cell growth to ca. $70 \%$, while for HCC2998 only an inhibition of $20 \%$ is observed (Figure S7 $\mathrm{A}$ and $\mathrm{B}$ ). These data indicate that FdU is slightly more cytotoxic than 5-FU, as expected, and that HCC2998 is less sensitive to these drugs than HTB-38. Colony assays also demonstrate that $\mathrm{FdU}_{10}$ oligomers can effectively diminish the rate of growth in both cell lines, circumventing the resistance of HCC2998.

The same assays were conducted using DNA nanostructures with $\mathrm{FdU}_{\mathrm{n}}$, see Figures 3 and 4 . For $\mathrm{Td}$ anchoring one strand of $\mathrm{FdU}_{10}(\mathrm{Td}-1 \mathrm{~F})$, little cytotoxicity is detected by MTT in HTB-38 and HCC2998 (Figure 3A and $B)$. Note that our nanostructures are compared with reference drugs at the same total number of equivalents of FdU (see Table S5). Through colony assays, no antiproliferative action of Td-1F in HTB-38 is observed (Figure 4A). However, in HCC2998 cells, Td-1F reduces the cell growth in ca. $20 \%$, inducing higher effect than 5-FU at $0.5 \mu \mathrm{M}$ (see Figure S7). 
A

HTB-38

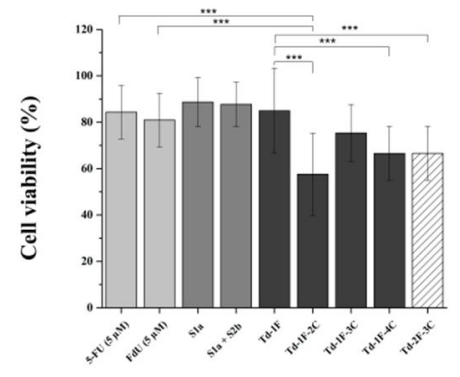

C

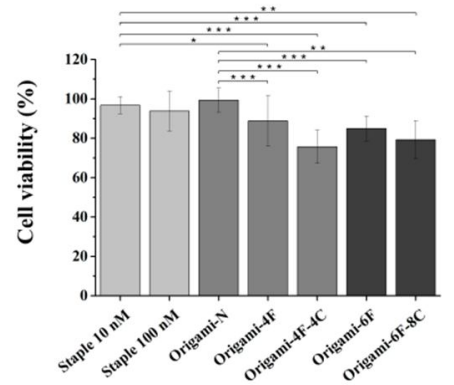

B

HCC2998

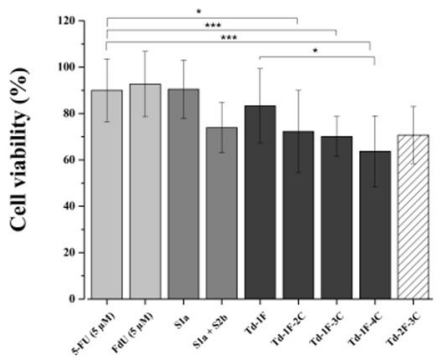

D

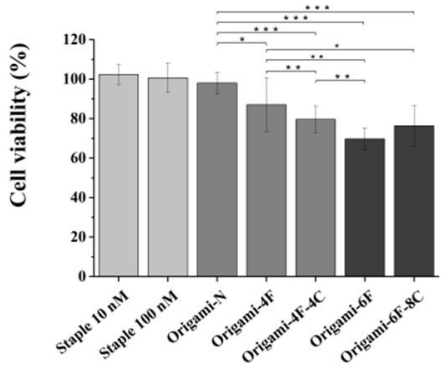

Fig 3. MTT cytotoxicity for the DNA nanostructures. Cells were treated with modified Td at $500 \mathrm{nM}$ ( $5 \mu \mathrm{M}$ in terms of $\mathrm{FdU}$ ) ( $\mathrm{A}$ and $\mathrm{B}$ ) and with origami at 2 nM DNA (100-150 nM of FdU) (C and D). Error bars represent standard deviation (SD) of three independent experiments in triplicate. * corresponds to $\mathrm{t}$ - test results with: $* p \leq 0.1, * * p \leq 0.05, * * * p \leq 0.01$ significantly different within each indicated pair.

In the case of DNA origami, the number of staples containing $\mathrm{FdU}_{\mathrm{n}}$ was varied, from four (Origami-4F) to six (Origami-6F), aiming at increasing the cytotoxic effect. The inclusion of 4 strands reduces slightly the values of cell viability by $15-20 \%$, resembling the $\mathrm{Td}$ effect. The additional FdU $\mathrm{n}_{\mathrm{n}}$ content ( 6 strands) increases the cytotoxic effect of DNA origami, only in HCC2998 (Figures $3 \mathrm{C}$ and $\mathrm{D}$ ), which is a good indication for its promising use as anticancer nanocarrier considering their large number of available loading positions. Surprisingly, in the colony formation assays, no antiproliferative effect is detected for DNA origami modified with six $\mathrm{FdU}_{\mathrm{n}}$ staples in both cell lines (Figures $4 \mathrm{C}$ and $\mathrm{D}$ ).

To increase the cytotoxic effect of $\mathrm{FdU}_{\mathrm{n}}$-functionalized DNA nanoscaffolds, cholesterol was selected as a potential enhancer of the cell entrance due to its recognized ability to interact with cell membrane. ${ }^{63-65}$ The results displayed in Figures 3A show that in the case of HTB-38 cells, the Td with only two cholesterol derivatives positioned in two different DNA strands (Chol-S3a and Chol-S4a) reveals the highest reduction in the percentage of viable cells, approximately $45 \%$. The increment of cholesterol (from 3 to 4 ) seems to add no additional cytotoxic effect to Td. In contrast, Td with a higher amount of cholesterol (Td-1F-4C) is the most cytotoxic in HCC2998 cells (Figure 3B). These findings show that depending on cell line, the number of cholesterols added to the nanostructure enhances the cytotoxic effects in different proportions.

Td with $\mathrm{FdU}_{10}$ and cholesterol produces a strong inhibition effect upon the proliferation of both types of cancer cells, being still efficient in HTB-38 cells even for a low number of cholesterol molecules attached (Figure 4A). If the maximum amount of cholesterol is anchored to $\mathrm{Td}$, the percentage of 
inhibition promoted is equal in HTB-38 and HCC2998. However, in the case of HCC2998 the antiproliferative effect produced is progressively increased with the number of cholesterols. These results clearly demonstrate that $\mathrm{Td}$, once modified, is a potent inhibitor of cancer cell growth and acts differently from 5-FU and FdU, with a closer resemblance to the mechanism followed by $\mathrm{FdU}_{10}$ which is able to overcome cell sensitivity (Figure S7). In Td with two staples modified with $\mathrm{FdU}_{10}, \mathrm{Td}-2 \mathrm{~F}-3 \mathrm{C}$, the same cytotoxic effect as that found for Td$1 F-3 C$ is observed, at the same $\mathrm{FdU}_{10}$ concentration, see MTT results (Figures $3 \mathrm{~A}$ and $\mathrm{B}$ ). However, that similarity is not observed in colony assays, i.e. Td$2 \mathrm{~F}-3 \mathrm{C}$ is not efficient in preventing cancer cell growth.

A

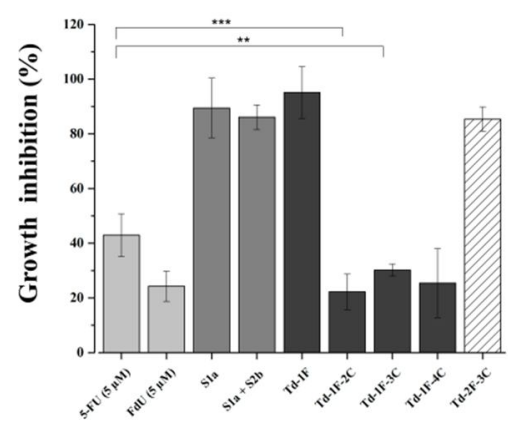

C

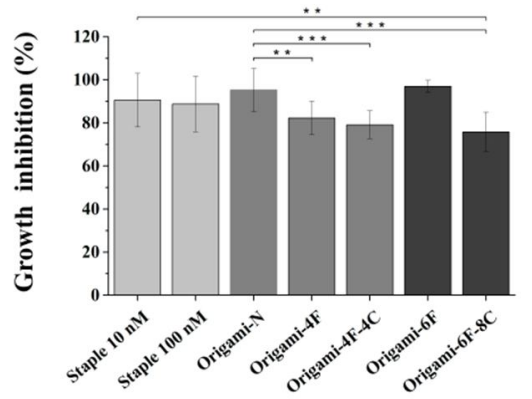

B $\quad$ HCC2998

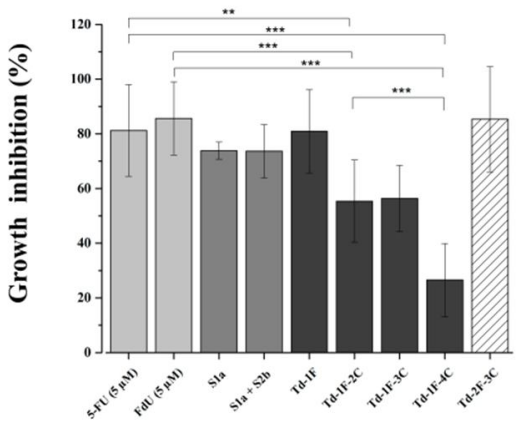

D

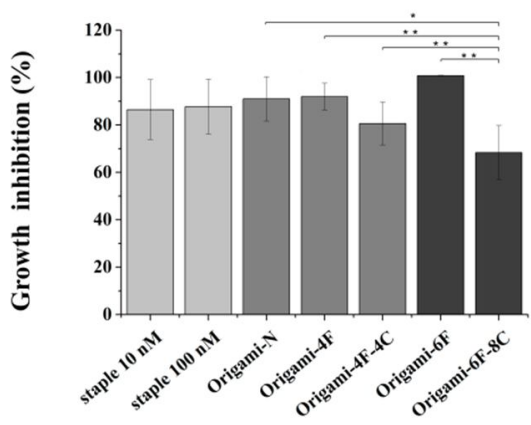

Fig 4. Growth inhibition assay for the two DNA nanostructures. Cells, of the indicated line were treated with modified $\mathrm{Td}$ at $500 \mathrm{nM}(5 \mu \mathrm{M}$ in terms of FdU) ( $A$ and $B$ ) and with DNA origami at $2 \mathrm{nM} \mathrm{(100-150} \mathrm{nM} \mathrm{of} \mathrm{FdU)} \mathrm{(C} \mathrm{and}$ D). Error bars represent standard deviation (SD) of three independent experiments in triplicate. *corresponds to t- test results with: $* p \leq 0.1$, $* * p \leq 0.05, * * * p \leq 0.01$ significantly different within each indicated pair.

Regarding DNA origami, the DNA origami 4F-4C represents an improvement when compared to the reference samples of 5-FU, FdU and origami deprived of cholesterol (Figure 3C and 3D). However, the progressive increase in the number of cholesterol from $4 \mathrm{C}$ to $8 \mathrm{C}$ (DNA origami-4F-4C and $6 \mathrm{~F}-8 \mathrm{C}$ ), led to a little increase in the cytotoxic effect after 48 hours of treatment. Colony results reveal almost the same trend as MTT. An important antiproliferative effect is only observed to DNA origami-6F-8C, demonstrating the benefic effect of cholesterol in the attachment of DNA origami to the cells (Figure 4C and 4D). Comparing to Td, DNA origami is less efficient in the reduction of 
cancer cell growth. These results are in good agreement with the ones reported for $\mathrm{Td}$, in which applying a lower concentration of $\mathrm{Td}$ ( $\mathrm{Td}-2 \mathrm{~F}-3 \mathrm{C}$ ), reduces the antiproliferative action of the nanocarrier (Figures 4A and 4B). Thus, we may hypothesize that the concentration of DNA assembles plays an important role in terms of the number of active nanocarriers attached or internalized into the cells.

Cholesterol as a promoter of cellular uptake. For the study of nanocarriers' cell uptake using confocal microscopy and flow cytometry, fluorescently modified DNA nanoscaffolds were assembled. Td complementary staples were synthesized with the fluorescent dyes, cyanine dye 3 (Су3) and fluorescein isothiocyanate (FITC), anchored to the 5'-end of an external strand, S5 oligonucleotide (Figure 1B and Table S1). SYBRGreen was intercalated as fluorescent marker in DNA origami and the remaining free dye removed through purification (Figure 2D). Each fluorescent dye was used according to experimental requirements. The number of cholesterol moieties introduced in each DNA nanostructure was 2 in Td and, 4 and 8 in DNA origami.

Flow cytometry assays show a slight displacement of Td compared to control samples, while the addition of cholesterol seems to have no effect or even be moderately detrimental for $\mathrm{Td}$ cell entrance, in both cell lines (Figure 5A). On the other hand, by inspecting confocal images (Figure 5B) a high amount of Td internalized in HTB-38 cells is identified, but no significant differences are encountered between $\mathrm{Td}$ in the absence or presence of cholesterol.
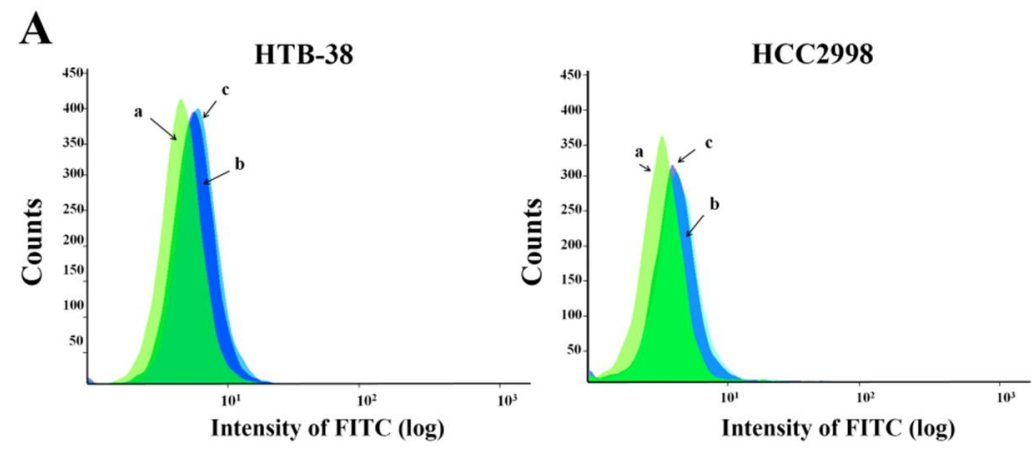

B
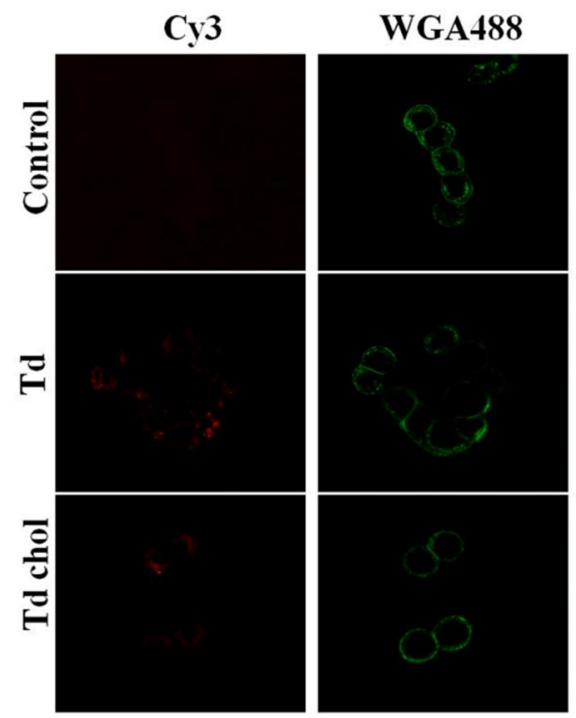

Merged

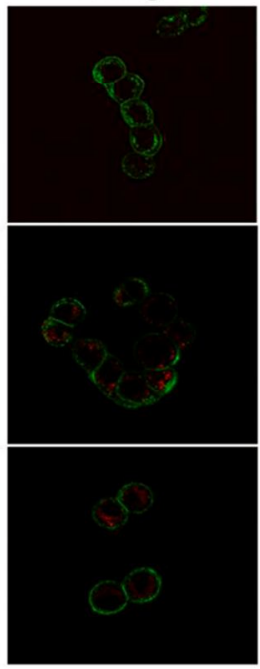

Fig 5. Intracellular uptake of DNA Td in colorectal cancer cells. In both assays, cells were incubated separately with the native and modified DNA 
Td. In A, DNA Td internalization measured in both cell lines through flow cytometry. Label (a) corresponds to control buffer, (b) is Td without cholesterol moieties and (c) is Td plus two cholesterol moieties (Td-1F-2CFITC). B, Laser scanning confocal analysis of the uptake of unmodified Td (Td-1F) and modified Td bearing two strands incorporating cholesterol (Td1F-2C-Cy3) in HTB-38 cells, after 24 hours of exposure. Cy3 shows the presence of Td labeled in red, WGA488 show the cell membrane stained in green with WGA488 and merged show the superposition of the two fluorescent probes.

Figure 6A shows the internalization profiles obtained for DNA origami in the presence of a different number of cholesterol moieties. SYBRGreen shows to be internalized to a larger extent when intercalated in DNA origami, than in the control, SYBRGreen solution. The displacement of DNA origami into the cells is progressively larger when four and eight cholesterol moieties are attached to origami.

The confocal microscopy images shown in Figure 6B further sustain flow cytometry outcomes, clearly indicating the presence of DNA origami inside HTB-38. A higher concentration of origami is detected inside the cells if cholesterol is attached to the nanocarrier. Differences between DNA origami with increasing content of cholesterol are not discernible.

After 24 hours, both DNA nanostructures show to be predominantly located in cytoplasm, apparently confined to specific organelles, as endosomes or lysosomes. ${ }^{50,51}$ It should be noted that due to the low number of staples used to engineer $\mathrm{Td}$, the simultaneous anchoring of cholesterol and fluorescent dyes limits the number of cholesterol moieties to two. In comparison, both nanoscaffolds are efficiently taken up into the cells, but DNA origami especially benefits from the incorporation of cholesterol derivatives. 
A

HTB-38

HCC2998

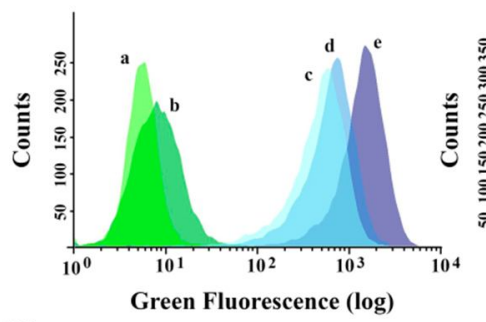

B

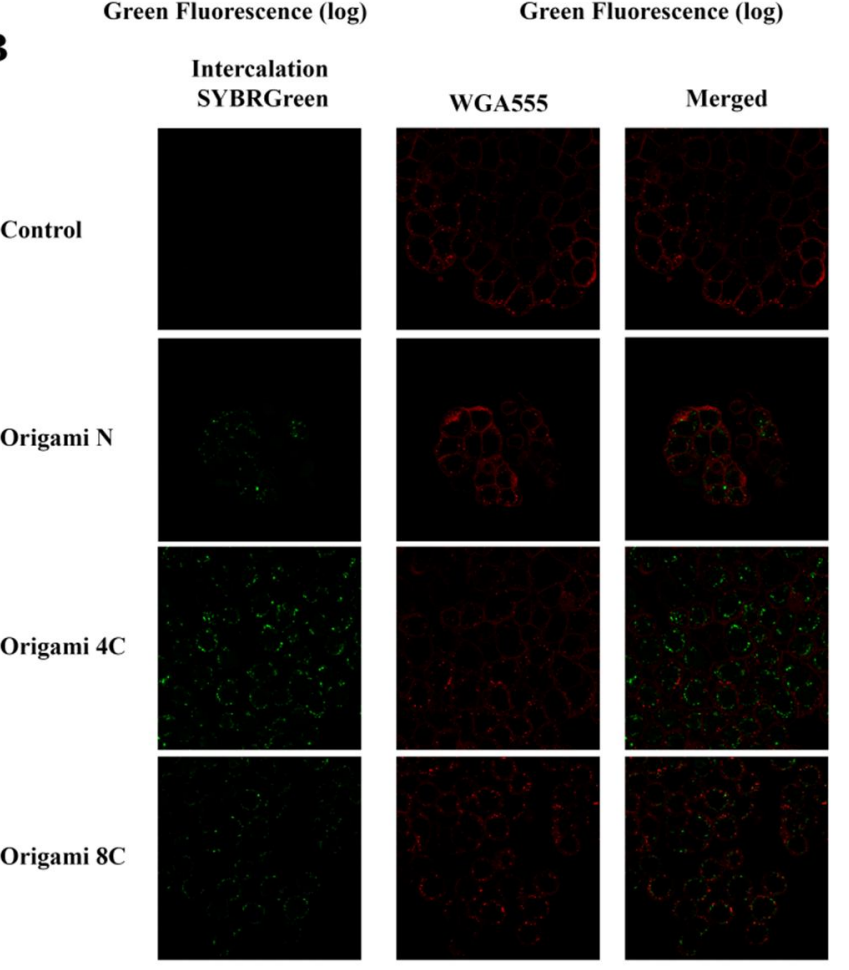

Fig 6. Intracellular uptake of DNA origami in colorectal cancer cells. In both assays, cells were incubated separately with the native and modified DNA origami. In A, DNA origami internalization measured in both cell lines through flow cytometry. Label (a) corresponds to control buffer, (b) is the solution of SYBRGreen, (c) represents native DNA origami, (d) and (e) stands for DNA origami with 4 and 8 cholesterol moieties, respectively. $B$, Laser scanning confocal analysis of the uptake of native DNA origami, 4 and 8 cholesterol strands modified DNA origami in HTB-38 cells, after 24 hours of exposure. (SYBRGreen) show the presence of DNA origami labeled in green, (WGA555) show the cell membrane stained in red with WGA555 and (merged) show the superposition of the two fluorescent probes.

Apoptosis induction. Apoptosis assays were conducted to compare $\mathrm{Td}$ and DNA origami effects on cell death and identify the cellular death mechanism involved in the reduction of cell viability. As anticipated by previous assays, HTB-38 cells display higher percentages of cell apoptosis and necrosis than HCC2998 (Figure 7). Apoptosis results resemble the profiles found in the MTT assay, thus validating the consistency of our data. Based on data obtained for the Td in HTB-38 (Figure 7A), it may be inferred that there is a dependency of the cellular death processes on the disposition and the number of modifications in the nanostructure backbone, as shown by MTT. 


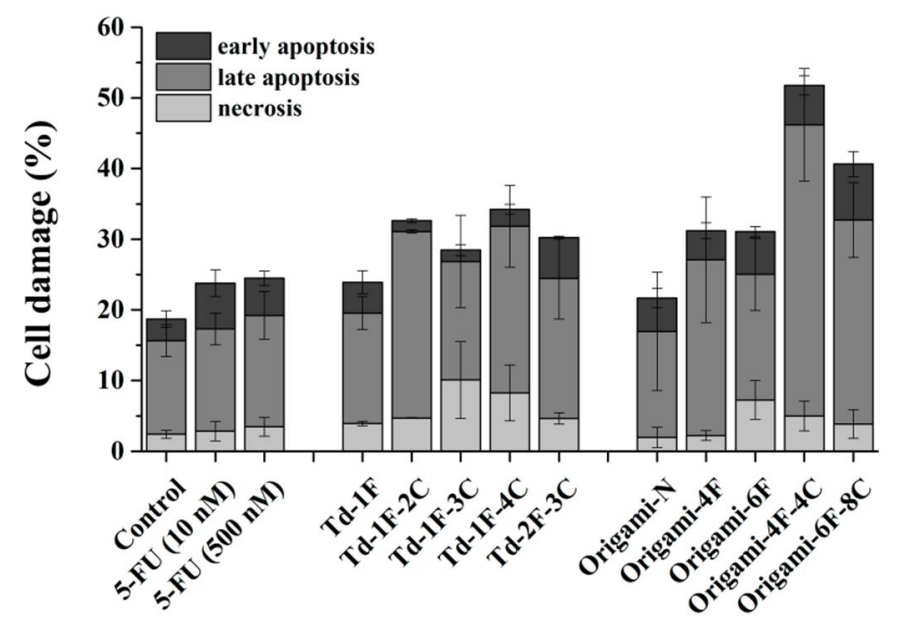

B

HCC2998

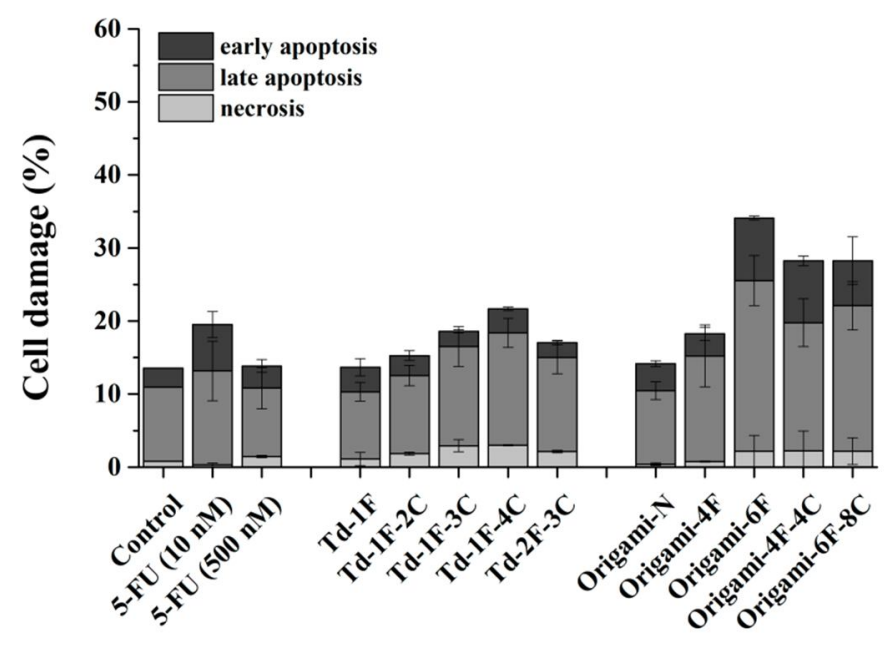

Fig 7. Apoptosis assay comparing 5-FU and modified DNA nanostructures, DNA tetrahedron and DNA origami in A, HTB-38 and B, HCC2998 cell lines. Error bars represent standard deviation (SD) of two independent experiments in duplicate.

In comparison, $\mathrm{Td}-1 \mathrm{~F}-3 \mathrm{C}$ and $\mathrm{Td}-2 \mathrm{~F}-3 \mathrm{C}$ leads to different proportions of early apoptosis and necrosis, but comparable values of total cell damage. HCC2998 cells, conversely, do not present an influence on modifications disposition but essentially it seems to be the number of cholesterol added that has higher impact. For DNA origami the inclusion of staples modified with FdU ${ }_{n}$ and cholesterol leads to an increase in the ability to promote cell damage proved by both MTT and apoptosis assays (Figure 3 and 7).

From the comparison of the two nanoscaffolds, we observe comparable abilities to trigger the cellular death processes, even employing distinct $\mathrm{FdU}_{\mathrm{n}}$ concentrations (origami $=110-150 \mathrm{nM}$; $\mathrm{Td}=5 \mu \mathrm{M}$ ). In general, it is observed a larger tendency of Td to induce cell necrosis than DNA origami, proving its higher cytotoxicity observed in MTT and colony assays, compatible with the higher concentration of $\mathrm{FdU}_{\mathrm{n}}$. 
Nevertheless, the two DNA origami with cholesterol modifications, DNA origami-4F-4C and 6F-8C, are more effective in promoting apoptosis than the fully loaded Td (Td-1F-4C).

\section{Experimental}

\section{Preparation of DNA tetrahedron}

Standard and modified DNA strands at $2.5 \mu \mathrm{M}$ were mixed in $10 \mathrm{nM}$ Tris, 5 $\mathrm{mM} \mathrm{MgCl} 2$ at an equal molar ratio, having a final strand concentration of DNA $\mathrm{Td}$ equal to $2.5 \mu \mathrm{M}$. The solution was heated to $95{ }^{\circ} \mathrm{C}$ for $4 \mathrm{~min}$ and rapidly cooled to $4{ }^{\circ} \mathrm{C}$, following the procedure of Turberfield and co-workers. ${ }^{46}$ To attach fluorescent dyes, tetrahedral structures were firstly assembled and then the complementary strand (Cy3-S5 or fluorescein-S5) was added at 2.5 $\mu \mathrm{M}$. This mixture was allowed to hybridize at room temperature for $24 \mathrm{~h}$. Final molar concentration of $\mathrm{Td}$ and the number of equivalents of FdU used in experiments are compiled in Table S5. We chose to compare the DNA nanoparticles with control drugs assuming that all the $\mathrm{FdU}_{\mathrm{n}}$ oligomers are converted into the active metabolite, FdU monophosphate.

\section{Preparation of DNA origami}

DNA origami were assembled following the method developed by Rothemund. ${ }^{43}$ Modified and unmodified helper strands were mixed with the scaffold, a circular genomic DNA from the virus M13mp18, at molar ratio of 10:5:1. The origami was assembled using a Biorad Termocycler starting at 85 ${ }^{\circ} \mathrm{C}$ and decreased to room temperature overnight. Subsequently, the DNA origami was purified by centrifugation at $4{ }^{\circ} \mathrm{C}$. Finally, the buffer was replaced by PBS plus $4 \mathrm{mM} \mathrm{MgCl} 2$ through centrifugation. DNA origami used in flow cytometry and confocal microscopy were labeled with SYBRGreen, The nanostructures after heat and cold down were incubated with $1 \mu \mathrm{L}$ of $1 / 200$ ( v/v) SYBRGreen solution in PBS for $1 \mathrm{~h}$ at room temperature. As a control, a solution of DNA origami buffer was incubated with the same SYBRGreen solution. Then, all the samples were purified by centrifugation and quantified. Final molar concentrations of DNA origami and the number of equivalents of FdU used in experiments are compiled in Table S5.

\section{AFM imaging}

For tetrahedron visualization, an aliquot of $5 \mu \mathrm{L}$ of sample at $10 \mathrm{nM}$ was diluted in $300 \mu \mathrm{L}$ buffer ( $10 \mathrm{nM}$ Tris, $15 \mathrm{mM} \mathrm{MgCl}$ plus $2 \mathrm{mM} \mathrm{NiCl} 2$ ) and placed on freshly cleaved mica for $30 \mathrm{~min}$. In the case of the DNA origami visualization, $1 \mu \mathrm{L}$ of sample was deposited on a mica surface and left to adsorb for 1 minute, and then $60 \mu \mathrm{L}$ of TAE- $\mathrm{Mg}^{2+}$ buffer $(40 \mathrm{mM}$ Tris $\mathrm{pH} 8.0$, $12.5 \mathrm{mM} \mathrm{Mg}^{2+}$ ).

\section{Size measurements}

The hydrodynamic diameter of DNA nanostructures modified with $\mathrm{FdU}_{\mathrm{n}}$ were measured by dynamic light scattering using a DLS with a Zetasizer nano ZS (Malvern Instruments, Malvern, UK). After assembling, samples were measured in duplicate at room temperature with a detection angle of $173^{\circ}$. All correlation functions were fitted using the cumulant algorithm from Malvern 
software for calculate the mean size (average particle size of a population) or $Z$-average and the polydispersity index from the single exponential fitting of the correlation function, as recommended by ISO 13321.

\section{TEM}

Td modified with $\mathrm{FdU}_{10}$ and cholesterol at $10 \mathrm{nM}$ was adsorbed onto glowdischarged, carbon-coated TEM grids. Afterwards, grids were stained for 10 seconds adding $2 \%$ aqueous uranyl formate solution with $25 \mathrm{mM} \mathrm{NaOH}$.

\section{Agarose gel electrophoresis}

Agarose concentrations of $2.5 \%$ and $1 \%$ (wt/vol) were used to prepare the gels for analysis of $\mathrm{Td}$ and DNA origami, respectively. TAE buffer (1x) supplemented with $125 \mathrm{mM} \mathrm{MgCl}_{2}$ and $5 \mathrm{mM}$ EDTA was used to prepare and run the gels, stained with SYBRGreen for DNA detection. The amount of the Td and DNA origami loaded in the gel was 140 nmols and 10 nmols, respectively. The gels were run at $100 \mathrm{~V}$ for approximately $50 \mathrm{~min}$ and then photographed under UV light. In the case of Td, gels were run at $4{ }^{\circ} \mathrm{C}$ and 100 bp DNA ladder was used. For DNA origami three different ladders were used, 10, $50 \mathrm{bp}$ and $1 \mathrm{Kd}$ ladders.

\section{I nternalization by flow-cytometry}

To assess the level of internalization of DNA-based nanostructures modified with $\mathrm{FdU}_{\mathrm{n}}$ the following procedure was conducted. Cells were seeded in 24-

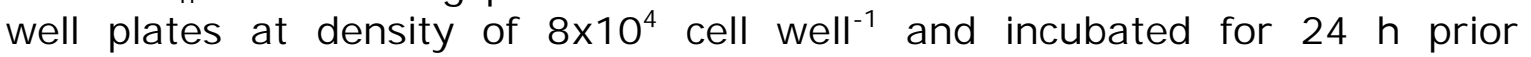
experiment. The reference drugs 5-FU and FdU were initially dissolved in DMSO and dissolved in fresh growth medium. The final concentration of DMSO in cell medium was of $0.5 \%(\mathrm{v} / \mathrm{v})$. After 24 hours samples addition, cells were washed once with 1xPBS (phosphate buffer saline) and harvested by treatment with trypsin, taken up in cell culture medium and centrifuged at $1000 \mathrm{rpm}$ for $5 \mathrm{~min}$. This procedure was repeated twice using 1xPBS and the remaining supernatant was suspended in cold PBS. In the case of Td, Td modified and respective control sample were stained with fluorescein and additionally propidium iodide (PI) was added to stain dead cells. DNA origami were stained with SYBRGreen before adding to the cells and only PI was added after cells treatment.

\section{Confocal microscopy}

To assess the level of internalization of DNA-based nanostructures modified with different number of cholesterol moieties by confocal microscopy the following procedure was conducted. Cells were seeded in 4-well plates at density of $8 \times 10^{3}$ cell well $^{-1}$ and incubated for $24 \mathrm{~h}$ prior experiment. The DNA nanostructures were added directly to the cells dissolved in fresh growth medium and incubated. After 24 hours samples addition, cells were washed once with cold PBS (phosphate buffer saline, $10 \mathrm{mM}$ Hepes) and incubated with WGA $0.2 \mathrm{\mu g} \mathrm{ml}^{-1}$ in the same solution for $30 \mathrm{~min}$ at $4{ }^{\circ} \mathrm{C}$ to specifically bind to the cell membrane. Then the cells were washed twice with cold PBS. In the case of $\mathrm{Td}$, Td was hybridized with a complementary strand conjugated with Cy3 and DNA origami were stained with SYBRGreen.

\section{Apoptosis by flow-cytometry}


The proportion of apoptotic cells resulting from exposition to the drug was evaluated by flow cytometry combining fluorescein isothiocyanate (FITC)Annexin $\mathrm{V}$ and $\mathrm{PI}$. Cells were seeded in duplicate in 24-well plates with a density of $5 \times 10^{4}$ cell well $^{-1}$. Cells were treated with 5 -FU, FdU and $\mathrm{FdU}_{\mathrm{n}}$ - and cholesterol-modified nanostructures and incubated for 48 hours. The reference drugs 5-FU and FdU were initially dissolved in DMSO and dissolved in fresh growth medium. The final concentration of DMSO in cell medium was of $0.5 \%(\mathrm{v} / \mathrm{v})$. Attached cells were harvested with trypsin and floating cells were washed twice in cold PBS, pelletted and resuspended in Annexin binding buffer plus FITC-Annexin V and PI according to the manufacturer's specifications. After staining, samples were analyzed by flow cytometry.

\section{MTT assay}

To determine the effect of 5-FU, FdU and $\mathrm{FdU}_{\mathrm{n}}$ - and cholesterol-modified nanostructures on cell viability, the method of MTT (1-(4,5-dimethylthiazol-2yl)-3,5-diphenylformazan) reduction was carried out, following the procedure used by the National Cancer Institute in vitro Anticancer Drug Discovery Screen Program. ${ }^{66}$ HTB-38 and HCC2998 cell lines were seeded at $1 \times 10^{4}$ cell well $^{-1}$ in 96 -well plate after ensuring that the seeding density was suitable to guarantee $80 \%$ confluence during experiment completion. After $24 \mathrm{~h}$ of plating, samples were added in the medium to the cells dissolved in sterile saline buffers; $10 \mathrm{nM}$ Tris, $5 \mathrm{mM} \mathrm{MgCl}$ or PBS plus $4 \mathrm{mM} \mathrm{MgCl} 2$ in the case of $\mathrm{Td}$ and DNA origami, respectively, and the respective negative controls were included in the experiment. The reference drugs 5-FU and FdU were initially dissolved in DMSO and dissolved in fresh growth medium. The final concentration of DMSO in cell medium was of $0.5 \%(\mathrm{v} / \mathrm{v})$. Cells were incubated with drug for 48 hours at $37^{\circ} \mathrm{C}$ under $5 \% \mathrm{CO}_{2}$. After this time, the MTT reagent was added to a final concentration of $0.5 \mathrm{mg} \mathrm{mL}^{-1}$ to each well and incubated for 3 hours. The MTT reduction was read at a single wavelength of $570 \mathrm{~nm}$.

\section{Colony assay}

The percentage of cell survival after exposing colon cells to the different forms of cytostatic drug was evaluated through colony assays. Before treatment, cells were plated at $2.5 \times 10^{3}$ cell well $^{-1}$ in a 24 -well and allowed to adhere for $24 \mathrm{~h}$. Cells were treated with 5-FU, FdU and DNA-based nanostructures for 24 h. The reference drugs 5-FU and FdU were initially dissolved in DMSO and dissolved in fresh growth medium. The final concentration of DMSO in cell medium was of $0.5 \%(\mathrm{v} / \mathrm{v})$. After this time, medium was removed, cells were harvested through trypsinization, gently disaggregated and re-plated in triplicate at a density of $1 \times 10^{3}$ cell well $^{-1}$. The plates were placed in the incubator for at least 10 days to allow colonies to form. For colonies analysis, cells were washed once with 1xPBS, fixed with glutaraldehyde, washed twice with 1xPBS and stained in crystal violet. The percentage of survival cells was determined by measuring the absorbance of crystal violet at $590 \mathrm{~nm}$.

\section{Statistical analysis}

Each experiment was conducted at least in triplicate $(n>3)$. The statistical significance of replicates was analyzed using the Student's t-test with $* \mathrm{p} \leq$ $0.1, * * \mathrm{p} \leq 0.05, * * * \mathrm{p} \leq 0.01$. 


\section{Conclusions}

In this work, we investigated in comparison the unique properties of biocompatible DNA-based nanoscaffolds, DNA tetrahedron and rectangle DNA origami, as anticancer nanocarriers. To the best of our knowledge, our findings represent the first evidence that DNA-based nanostructures are efficient systems for the delivery of $\mathrm{FdU}_{\mathrm{n}}$ oligonucleotides, inducing higher in vitro cytotoxic and antiproliferative effect in colorectal cancer cells than the conventional drugs, 5-FU and FdU. Importantly, the oligomeric FdU shows an effective cytotoxic activity able to overcome the sensitivity presented by HCC2998 cell lines, revealing the use of $\mathrm{FdU}_{\mathrm{n}}$ as a good alternative to these drugs. By designing the DNA nanostructures with a different number of complementary oligonucleotides bearing $\mathrm{FdU}_{\mathrm{n}}$ in the $\mathrm{3}^{\prime}$-end, we are able to rationally control the cytotoxic effect of the tridimensional templates. The hydrophobic cholesterol showed to be a good promoter of cell uptake, while maintaining the structural integrity of nanocarriers. The incorporation of a different number of cholesterol moieties revealed a meaningful modulation of the cytotoxic activity of $\mathrm{FdU}_{\mathrm{n}}$-modified $\mathrm{Td}$ and DNA origami, which in most of the cases is directly correlated with this number. In the case of DNA origami, it is evident that cholesterol clearly acts as a promoter of nanocarriers-cell membrane interaction. The propensity of cholesterol to aggregate individual $\mathrm{Td}$ nanostructures represents an additional contribution for the increment of $\mathrm{FdU}_{\mathrm{n}}$-nanostructures uptake.

In comparison, both DNA-based nanostructures, even carrying substantially different $\mathrm{FdU}_{\mathrm{n}}$ concentrations (DNA origami has 33 to 45fold less $\mathrm{FdU}_{\mathrm{n}}$ than $\mathrm{Td}$ ) they produce comparable cytotoxic effects, albeit different antiproliferative actions. The antiproliferative action seems to be governed by the nanocarrier concentration. However, the presence of cholesterol in DNA nanoscaffolds boosts their antiproliferative action. The lower complexity of $\mathrm{Td}$ allows administering $\mathrm{FdU}_{\mathrm{n}}$ at higher concentrations than DNA origami. As the latter is able to induce higher levels of apoptosis, their cytotoxic action becomes equivalent. Thus, considering the high number of positions that may be modified in DNA origami, we may envisage its large potential for reaching higher levels of cytotoxicity and cell growth inhibition. The results described here encourage the development of DNA-based nanoscaffolds, in which precise densities of effective anticancer drugs and biomimetic targeting compounds at programmable spatial orientations may be synthetically included, opening the opportunity of achieving a finely tailored cancer treatment.

\section{Conflicts of interest}

There are no conflicts to declare. 


\section{Acknowledgements}

We acknowledge Dr Diego Arango for kindly provide colorectal cancer cell lines and $\mathrm{Dr}$ Susana Vilchez for technical advice and support to DLS experiments. Financial support by the Spanish Ministerio de Ciencia e Innovación (MICINN) (Project CTQ2014-52588R) and (Explora project CTQ2014-61758-EXP) are gratefully acknowledged. CIBER-BBN is an initiative funded by the VI National R + D + I Plan 2008-2011, Iniciativa Ingenio 2010, Consolider Program, CIBER Actions and financed by the Instituto de Salud Carlos III with assistance from the European Regional Development Fund. A.F.J. acknowledges Fundação para a Ciência e Tecnologia (FCT), Portugal, for financial support regarding Post-Doctoral grant SFRH/BPD/104544/2014. CQC is supported by FCT through the projects Pest-OE-QUI/UI0313/2014 and POCI-01-0145-FEDER007630 .

\section{Notes and references}

1. J. A. Meyerhardt and R. J. Mayer, New. Engl. J. Med., 2005, 352, 476-487.

2. J. Hyslop, A. Paul, K. Murphy and S. Fishburn, Colorectal cancer: the diagnosis and management of colorectal cancer, National Collaborating Centre for Cancer, 2011.

3. R. M. Wohlhueter, R. S. Mclvor and P. G. Plagemann, J cell physiol, 1980, 104, 309-319.

4. H. Sommer and D. V. Santi, Biochem Biophys Res Commun, 1974, 57, 689-695.

5. D. V. Santi, C. S. McHenry and H. Sommer, Biochemistry, 1974, 13, 471-481.

6. P. V. Danenberg and A. Lockshin, Pharmacol Ther, 1981, 13, 69-90.

7. M. Goulian, B. M. Bleile, L. M. Dickey, R. H. Grafstrom, H. A. Ingraham, S. A. Neynaber, M. S. Peterson and B. Y. Tseng, Adv Exp Med Biol, 1986, 195 89-95.

8. J. A. Houghton, F. G. Harwood and D. M. Tillman, Proc Natl Acad Sci U S A, 1997, 94, 8144-8149.

9. D. B. Longley, D. P. Harkin and P. G. Johnston, Nature rev. Cancer, 2003, 3, 330-338.

10. R. Kanamaru, H. Kakuta, T. Sato, C. Ishioka and A. Wakui, Cancer chemoth pharm 1986, 17, 43-46.

11. D. V. Santi and L. W. Hardy, Biochemistry, 1987, 26, 8599-8606.

12. K. Ghoshal and S. T. Jacob, Cancer Res, 1994, 54, 5.

13. D. W. Kufe and P. P. Major, J biol chem, 1981, 256, 9802-9805. 
14. K. Randerath, W. C. Tseng, J. S. Harris and L. J. Lu, Recent results in cancer research. Progres dans les recherches sur le cancer, 1983, 84, 283-297.

15. E. Chu, D. M. Koeller, P. G. Johnston, S. Zinn and C. J. Allegra, Mol Pharmacol, 1993, 43, 527-533.

16. R. B. Diasio and B. E. Harris, Clin Pharmacokinet, 1989, 16, 215-237.

17. W. A. Hammond, A. Swaika and K. Mody, Ther adv med oncol 2016, 8, 57-84.

18. C. Focaccetti, A. Bruno, E. Magnani, D. Bartolini, E. Principi, K. Dallaglio, E. O. Bucci, G. Finzi, F. Sessa, D. M. Noonan and A. Albini, PLoS One, 2015, 10, e0115686.

19. J. A. Houghton, P. J. Houghton and R. S. Wooten, Cancer Res, 1979, 39, 2406-2413.

20. M. W. Saif, Clinical colorectal cancer, 2005, 5, 89-100.

21. J. Cassidy, L. Saltz, C. Twelves, E. Van Cutsem, P. Hoff, Y. Kang, J. P. Saini, F. Gilberg and D. Cunningham, Ann Oncol, 2011, 22, 26042609.

22. J. Y. Douillard, P. M. Hoff, J. R. Skillings, P. Eisenberg, N. Davidson, P. Harper, M. D. Vincent, B. C. Lembersky, S. Thompson, A. Maniero and S. E. Benner, J clin oncol, 2002, 20, 3605-3616.

23. S. Sakuramoto, M. Sasako, T. Yamaguchi, T. Kinoshita, M. Fujii, A. Nashimoto, H. Furukawa, T. Nakajima, Y. Ohashi, H. Imamura, M. Higashino, Y. Yamamura, A. Kurita and K. Arai, New. Engl. J. Med., 2007, 357, 1810-1820.

24. P. Matt, B. van Zwieten-Boot, G. Calvo Rojas, H. Ter Hofstede, R. Garcia-Carbonero, J. Camarero, E. Abadie and F. Pignatti, Oncologist, 2011, 16, 1451-1457.

25. A. d. de Gramont, A. Figer, M. Seymour, M. Homerin, A. Hmissi, J. Cassidy, C. Boni, H. Cortes-Funes, A. Cervantes and G. Freyer, J clin oncol, 2000, 18, 2938-2947.

26. P. M. Wilson, P. V. Danenberg, P. G. Johnston, H. J. Lenz and R. D. Ladner, Nat rev. Clin oncol, 2014, 11, 282-298.

27. U. Vanhoefer, A. Harstrick, W. Achterrath, S. Cao, S. Seeber and Y. M. Rustum, J. Clin. Oncol., 2001, 19, 1501-1518.

28. W. H. Gmeiner, W. Debinski, C. Milligan, D. Caudell and T. S. Pardee, Future Oncol, 2016, 12, 2009-2020.

29. J. Liu, J. Kolath, J. Anderson, C. Kolar, T. A. Lawson, J. Talmadge and W. H. Gmeiner, Antisense Nucleic Acid Drug Dev, 1999, 9, 481-486.

30. Z. Y. Liao, O. Sordet, H. L. Zhang, G. Kohlhagen, S. Antony, W. H. Gmeiner and Y. Pommier, Cancer Res, 2005, 65, 4844-4851.

31. S. P. Chandran, S. B. Natarajan, S. Chandraseharan and M. S. B. M. Shahimi, J Cancer Res and Practice, 2017, 4, 45-48.

32. J. Li, C. Fan, H. Pei, J. Shi and Q. Huang, Adv. mater., 2013, 25, 4386-4396. 
33. H. Lee, A. K. Lytton-Jean, Y. Chen, K. T. Love, A. I. Park, E. D. Karagiannis, A. Sehgal, W. Querbes, C. S. Zurenko, M. Jayaraman, C. G. Peng, K. Charisse, A. Borodovsky, M. Manoharan, J. S. Donahoe, J. Truelove, M. Nahrendorf, R. Langer and D. G. Anderson, Nat nanotechnol, 2012, 7, 389-393.

34. E. Winfree, F. Liu, L. A. Wenzler and N. C. Seeman, Nature, 1998, 394, 6.

35. J. H. Chen and N. C. Seeman, Nature, 1991, 350, 631-633.

36. R. P. Goodman, M. Heilemann, S. Doose, C. M. Erben, A. N. Kapanidis and A. J. Turberfield, Nat nanotechnol, 2008, 3, 93-96.

37. R. P. Goodman, R. M. Berry and A. J. Turberfield, Chem Commun, 2004, DOI: 10.1039/b402293a, 1372-1373.

38. J. Zimmermann, M. P. Cebulla, S. Mönninghoff and G. von Kiedrowski, Angew Chem Int Edit, 2008, 47, 3626-3630.

39. F. A. Aldaye and H. F. Sleiman, J. Am. Chem. Soc., 2007, 129, 13376- 13377.

40. C. M. Erben, R. P. Goodman and A. J. Turberfield, Journal of the American Chemical Society, 2007, 129, 6992-6993.

41. C. Zhang, M. Su, Y. He, Y. Leng, A. E. Ribbe, G. Wang, W. Jiang and C. Mao, Chem Commun 2010, 46, 6792-6794.

42. M. Tintore, R. Eritja and C. Fabrega, Chembiochem, 2014, 15, 13741390.

43. P. W. Rothemund, Nature, 2006, 440, 297-302.

44. P. K. Lo, K. L. Metera and H. F. Sleiman, Curr opin chem biol, 2010, 14, 597-607.

45. D. Bousmail, L. Amrein, J. J. Fakhoury, H. H. Fakih, J. C. Hsu, L. Panasci and H. F. Sleiman, Chem Sci, 2017, 8, 6218-6229.

46. R. P. Goodman, I. A. T. Schaap, C. F. Tardin, C. M. Erben, R. M. Berry, C. F. Schmidt and A. J. Turberfield, Science, 2005, 310, 16611665

47. K. R. Kim, H. Y. Kim, Y. D. Lee, J. S. Ha, J. H. Kang, H. Jeong, D. Bang, Y. T. Ko, S. Kim and H. Lee, J. Control. Release, 2016, 243, 121-131.

48. J. Li, H. Pei, B. Zhu, L. Liang, M. Wei, Y. He, N. Chen, D. Li, Q. Huang and C. Fan, ACS nano, 2011, 5, 8783-8789.

49. J. W. Keum, J. H. Ahn and H. Bermudez, Small, 2011, 7, 3529-3535.

50. L. Liang, J. Li, Q. Li, Q. Huang, J. Shi, H. Yan and C. Fan, Angew. Chem Int Edit, 2014, 53, 7745-7750.

51. A. S. Walsh, H. Yin, C. M. Erben, M. J. Wood and A. J. Turberfield, ACS nano, 2011, 5, 5427-5432.

52. C. E. Castro, F. Kilchherr, D. N. Kim, E. L. Shiao, T. Wauer, P. Wortmann, M. Bathe and H. Dietz, Nat Methods, 2011, 8, 221-229.

53. Q. Mei, X. Wei, F. Su, Y. Liu, C. Youngbull, R. Johnson, S. Lindsay, H. Yan and D. Meldrum, Nano letters, 2011, 11, 1477-1482. 
54. X. Shen, Q. Jiang, J. Wang, L. Dai, G. Zou, Z. G. Wang, W. Q. Chen, W. Jiang and B. Ding, Chem Commun 2012, 48, 11301-11303.

55. Q. Jiang, C. Song, J. Nangreave, X. Liu, L. Lin, D. Qiu, Z. G. Wang, G. Zou, X. Liang, H. Yan and B. Ding, J. Am. Chem. Soc., 2012, 134, 13396- 13403.

56. Y. X. Zhao, A. Shaw, X. Zeng, E. Benson, A. M. Nystrom and B. Hogberg, ACS nano, 2012, 6, 8684-8691.

57. V. J. Schuller, S. Heidegger, N. Sandholzer, P. C. Nickels, N. A. Suhartha, S. Endres, C. Bourquin and T. Liedl, ACS nano, 2011, 5, 9696-9702.

58. J. M. Mariadason, D. Arango, Q. Shi, A. J. Wilson, G. A. Corner, C. Nicholas, M. J. Aranes, M. Lesser, E. L. Schwartz and L. H. Augenlicht, Cancer res 2003, 63, 8791-8812.

59. K. Bracht, A. Nicholls, Y. Liu and W. Bodmer, Br J cancer, 2010, 103, 340.

60. C. H. Takimoto, L. K. Yee, D. J. Venzon, B. Schuler, F. Grollman, C. Chabuk, J. M. Hamilton, A. P. Chen, C. J. Allegra and J. L. Grem, Clin Cancer Res, 1999, 5, 1347-1352.

61. M. W. Saif, A. Choma, S. J. Salamone and E. Chu, J NCl: J Natl Cancer Inst, 2009, 101, 1543-1552.

62. J. L. Grem, Investigational New Drugs, 2000, 18, 299-313.

63. J. Soutschek, A. Akinc, B. Bramlage, K. Charisse, R. Constien, M. Donoghue, S. Elbashir, A. Geick, P. Hadwiger and J. Harborth, Nature, 2004, 432, 173-178.

64. M. Langecker, V. Arnaut, T. G. Martin, J. List, S. Renner, M. Mayer, H. Dietz and F. C. Simmel, Science, 2012, 338, 932-936.

65. M. Langecker, V. Arnaut, J. List and F. C. Simmel, Acc chem res, 2014, 47, 1807-1815.

66. A. Monks, D. Scudiero, P. Skehan, R. Shoemaker, K. Paull, D. Vistica, C. Hose, J. Langley, P. Cronise and A. Vaigro-Wolff, J. Natl. Cancer I., 1991, 83, 757-766. 


\section{Supporting Information}

\section{DNA-based nanoscaffolds as vehicles for 5-fluoro-2'-deoxyuridine oligomers in colorectal cancer therapy}

Andreia F. Jorge, * Anna Aviñó, Alberto A. C. C. Pais, Ramon Eritja* and Carme Fàbrega*

\section{Table of contents:}

1. Materials and methods

Page 2

2. Table S1: Modified staple strands sequences for tetrahedron and DNA

Page 5 origami.

3. Table S2: List of the helper strands used to engineer DNA origami

Page 7

4. Table S3: HPLC analysis and M ALDI-TOF characterization of modified

Page 14 staples required for DNA Td and DNA origami assembly

5. Table S4: Hydrodynamic sizes of DNA Td and DNA origami measured by Page 15 DLS

6. Table S5: Summarizes nanoscaffolds concentration and the total

Page 16 number of equivalents of FdU

7. Figure S1: Gel electrophoresis of the stability of Td

Page 17

8. Figure S2: Gel electrophoresis analysis and stability of DNA origami Page 17

9. Figure S3: Additional AFM images of DNA Td

Page 18

10. Figure S4: Additional AFM images of DNA origami

Page 19

11. Figure S5: Additional AFM images of DNA origami with modified

Page 19 staples.

12. Figure S6: Cell viability assay of 5-FU, FdU and $\mathrm{FdU}_{10}$.

Page 20

13. Figure S7: Growth inhibition assay of 5-FU, FdU and FdU 10 .

Page 21

14. References

Page 21 


\section{Material and methods}

Reagents: The standard phosphoramidites and ancillary reagents used on the oligonucleotide synthesis were obtained from Applied Biosystems and Link Technologies Ltd. 5'-Fluorescein CE phosphoramidite (FITC), Cyanine-3-CE phosphoramidite (Cyanine 540), 5'-Cholesterol-CE phosphoramidite and 5-FdU-CE phosphoramidite were acquired from Link Technologies. 5Fluoro-2'-deoxyuridine (FdU) was purchased from Alfa Aesar. Centrifugation devices Nanosep 10K omega were purchased to Pall Life Science. Matrix for MALDI-TOF experiments was composed by 2',4',6'-trihydroxiacetophenone monohydrate (THAP, Aldrich) and ammonium citrate dibasic (Fluka). Solvents for HPLC analysis were prepared using triethylammonium acetate (TEAA) and acetonitrile (Merck) as mobile phase. The rest of the chemicals are analytical reagent grade from commercial sources as specified. Circular genomic DNA from the virus M 13mp18, 10, 50, and 1Kbp DNA Ladders were purchased from New England Biolabs and 100 bp DNA Ladders from Promega. Control drug, 5-Fluorouracil (5-FU) was purchased from Sigma. Ultrapure water (Millipore) was used in all experiments. HTB-38 was purchased from American Type Culture Collection, Manassas, VA and HCC2998 cell line was kindly provided by Dr. Diego Arango (M olecular Oncology Group; CIBBIM-Nanomedicine, Vall d'Hebron Institut of Research (VHIR)). Both cell lines were grown in DMEM supplemented with $10 \%$ fetal bovine serum (FBS), 50 i.u ml ${ }^{-1}$ penicillin and $50 \mu \mathrm{g} \mathrm{ml}^{-1}$ streptomycin. Cultures were grown at $37^{\circ} \mathrm{C}$ in 5\% CO2 humidified atmosphere. Cell membrane dyes WGA-488 and WGA-555 were kindly provided by the confocal microscopy service (ThermoFisher). Annexin V-FITC kit was obtained from ThermoFisher and used following manufacturer's instructions.

Instrumentation: Modified staple-strands for engineer the two DNA nanostructures were synthesized on an ABI 3400 DNA Synthesizer (Applied Biosystems). Analytic RP-HPLC was performed on a Waters chromatography system using Nucleosil $120 \mathrm{C} 18$ (250x8mm) column. The HPLC solvent used were; $A, 5 \%$ ACN in $100 \mathrm{mM}$ triethylammonium acetate (TEAA) ( $\mathrm{pH}=7$ ) and solvent $\mathrm{B}, 70 \% \mathrm{ACN}$ in $100 \mathrm{mM}$ TEAA ( $\mathrm{pH}=7$ ). Mass spectra were recorded on a M ALDI Voyager DE RP time-of-flight (TOF) spectrometer (Applied Biosystems) equipped with nitrogen laser at $337 \mathrm{~nm}$ using a 3ns pulse. The matrix used contained 2,4,6-trihydroxyacetophenone (THAP, $10 \mathrm{mgmL}^{-1}$ in ACN/ water 1:1) and ammonium citrate (50 $\mathrm{mgmL}^{-1}$ in water). Molecular absorption spectra between 220 and $550 \mathrm{~nm}$ were recorded with a Jasco V650 spectrophotometer. The temperature was controlled with an 89090A Agilent Peltier device. Hellma quartz cuvettes were used. The DNA nanostructures were annealed in an Eppendorf 
thermocycler (Boeker). Gels were imaged with a Gene Genius Bioimaging system (Syngene). AFM images were obtained by liquid tapping on a Nanoscope $3 \mathrm{~A}$ Multimode 4 AFM, using Bruker SNL-10 ultra-sharp silicon tips. Imaging was then conducted using a TEM microscope, Jeol JEM 1010100 kv with CCD M egaview 1kxlk (CCIT- University of Barcelona). The MTT and colony assays were measured in an automated spectrophotometric plate reader Glomax multi detection system (Promega). Internalization and apoptosis assays were measured with a Guava easyCyte $^{\mathrm{TM}}$ flow cytometer (M illipore) and data was analysis with Guavasoft 3.1.1. The confocal images were acquired by using a TCS SP2 confocal microscope equipped with live cell chamber system (Leica).

Synthesis of modified oligonucleotides: Standard staple-strand oligonucleotides were purchased to Sigma. Modified staple-strands were synthesized on ABI 3400 DNA Synthesizer, using the 200-nmol scale synthesis and the standard protocols. FITC, FdU, cholesterol and Cy3 phosphoramidites were site-specifically inserted into the standard sequence oligonucleotide. $\mathrm{FdU}_{\mathrm{n}}$ oligonucleotides at the 3 '-end were introduced using controlled pore glass functionalized with a 3'-succinyl-5-FdU solid support. To this end, the FdU was dimethoxytritilated and then was treated with anhydride succinic to obtain the corresponding succinate. Finally, the controlled pore glass solid support with 5-FdU was prepared following standard protocol. ${ }^{1,2}$

Modified oligonucleotides were deprotected with ammonia solution overnight at room temperature, followed by $1 \mathrm{~h}$ at $55^{\circ} \mathrm{C}$. The FdU containing oligonucleotides were purified by OPC (oligonucleotide purified cartridge, Glen Research). The Cholesterol-staples were desalted by Sephadex G-25 with 30\% acetonitrile (NAP-10, GE Healthcare). All the oligonucleotide staples were analyzed by RP-HPLC (Table S3) using two different HPLC gradients with a flow rate of $1 \mathrm{mlmin}^{-1}$. For the modified FdU staples the gradient used was: 0-50\% acetonitrile in 20 min and for the modified staples with cholesterol, fluorescein and Cy3 moieties the gradient of acetonitrile was increased stepwise, starting with $0-15 \%$ in the initial $5 \mathrm{~min}, 15-40 \%$ over $1 \mathrm{~min}$ and $40-85 \%$ over the last $9 \mathrm{~min}$. The length and homogeneity of the oligonucleotides were checked by MALDI-TOF (Table S3). The modified oligonucleotide concentration was determined by absorbance measurements $(260 \mathrm{~nm})$ and their extinction coefficient calculated. These samples were kept dry at $-20 \stackrel{\circ}{ } \mathrm{C}$ until further use. All the modified oligonucleotides sequences are detailed in Table S1. The standard strands for the DNA origami and DNA tetrahedron assemble are described below in Table $\mathbf{S 2}$. 
DNA nanostructures stability in cell medium. DNA tetrahedron (70 nmols) and DNA origami samples (10 nmols) were dissolved in cell medium (DMEM plus 10\% Fetal bovine serum) and shacked at $37^{\circ} \mathrm{C}$ for different periods of time $(0,15,30,60,120,240,480$ min and $24 \mathrm{~h})$. At the desired time the samples were removed from the shaker and frozen until further use. Then the samples were verified by gel electrophoresis. $2.5 \%$ agarose in TAE/ $12.5 \mathrm{mM} \mathrm{M} \mathrm{g} \mathrm{buffer} \mathrm{and} \mathrm{run}$ for 50 min at $100 \mathrm{~V} 1 \%$ agarose gels with the same buffer for the DNA origami. In the case of Td gels were run at $4^{\circ} \mathrm{C}$. 
Table S1. M odified staple-strands sequences for DNA tetrahedron and DNA origami.

\begin{tabular}{|c|c|}
\hline \multicolumn{2}{|l|}{ DNA tetrahedron } \\
\hline \multirow{2}{*}{ S1- FdU 10} & AGGCAGTTGAGACGAACATTCCTAAGTCTGAAATTTATCACCCGCCATAGTAGACGTA \\
\hline & TCACC-(FdU) $)_{10}$ \\
\hline S2a & CTTGCTACACGATTCAGACT \\
\hline Chol-S2a & Chol-CTTGCTACACGATTCAGACT \\
\hline S2b & TAGGAATGTTCGACATGCGAGGGTCCAATACCGACGATTACAG \\
\hline \multirow[t]{2}{*}{ Chol-S2b-FdU 10} & Chol-TAGGAATGTTCGACATGCGAGGGTCCAATACCGACGA \\
\hline & TTACAG-(FdU) $)_{10}$ \\
\hline S3a & GGTGATAAAACGTGTAGCAA \\
\hline Chol-S3a & Chol-GGTGATAAAACGTGTAGCAA \\
\hline S3b & GCTGTAATCGACGGGAAGAGCATGCCCATCCACTACTATGGCG \\
\hline \multirow[t]{2}{*}{ Chol-S3b } & Chol-GCTGTAATCGACGGGAAGAGCATGCCCATCCACTACTAT \\
\hline & GGCG \\
\hline S4a - & CCTCGCATGACTCAACTGCC \\
\hline Chol-S4a & Chol-CCTCGCATGACTCAACTGCC \\
\hline S4b- & TGGTGATACGAGGATGGGCATGCTCTTCCCGACGGTATTGGAC \\
\hline \multirow[t]{2}{*}{ Chol-S4b } & Chol-TGGTGATACGAGGATGGGCATGCTCTTCCCGACGGTAT \\
\hline & TGGAC \\
\hline \multirow[t]{2}{*}{ S4c } & CCTCGCATGACTCAACTGCCTGGTGATACGAGGATGGGCATGCTCTTCCCGACGGTAT \\
\hline & TGGAC-TTGATGAATGGTGGGTGAGAGG \\
\hline Fluorescein-S5 & Fluorescein-ССТСТCACCCACCATTCATC \\
\hline Cy3-S5 & СУЗ-ССТСТСАСССАССАТТСАТС \\
\hline DNA origami & Sequence ( $5^{\prime}$ to $\left.3^{\prime}\right)$ \\
\hline$t-5 r 4 e-F d U_{13}$ & AAAGGCCGCTCCAAAAGGAGCCTTAGCGGAGT-(FdU) $)_{13}$ \\
\hline t-3r2f-FdU 14 & TGTAGCATAACTITCAACAGTTCTAATTGTA-(FdU) $)_{14}$ \\
\hline t3r4e-FdU 14 & GTTGCCACCTCAGAGCCGCCACCGCCAGAAT-(FdU) ${ }_{14}$ \\
\hline t5r2f-FdU 14 & AATGCCCCATAAATCCTCATTAAAAGAACCAC-(FdU) $)_{14}$ \\
\hline$t-3 r 8 e-F d U_{10}$ & AGTAATCTTCATAAGGGAACCGAACTAAAACA-(FdU) $)_{10}$ \\
\hline t3r6f-FdU 10 & CCGGAAACTAAAGGTGAATTATCATAAAAGAA-(FdU) $)_{14}$ \\
\hline Chol-t-3r14f & Chol-TTT-TCAGAAGCCTCCAACAGGTCAGGATTAAATA \\
\hline Chol-t-3r18f & Chol-TाT-CAAAATTAGGATAAAAATITTAGGATATTCA \\
\hline Chol-t5r14f & Chol-TाT-TCATTACCGAACAAGAAAAATAATAATTCTGT \\
\hline
\end{tabular}




\begin{tabular}{ll}
\hline Chol-t5r18f & Chol-TाT-AGGCGTTAGGCTTAGGTTGGGTTAAGCTTAGA \\
Chol-t-1r22f & Chol-TाT-GCTCATTCGCGTCTGGCCTTCCTGGCCTCAG \\
Chol-t1r22e & Chol-TाT-TTAACGTTCGGGAGAAACAATAACAGTACAT \\
Chol-t-1r30f & Chol-Tा-GAATAGCCACAAGAGTCCACTATTAAGCCGGC \\
Chol-t1r30e & Chol-Tा-GTGTAGCCCTGAGTAGAAGAACTACATTCTG \\
\hline
\end{tabular}

$\mathrm{FdU}_{\mathrm{n}} \mathrm{n}$ in subscript stands for the number of FdU monomers, Chol for a cholesterol moiety and Cy3 for Cyanine 540. 
Table S2. List of the helper strands used to engineer the DNA tetrahedron and DNA origami. All these oligonucleotides were purchased from commercial sources as described in the Materials and M ethods section.

\begin{tabular}{|c|c|}
\hline \multicolumn{2}{|c|}{20 bp regular DNA Tetrahedron } \\
\hline \multirow{2}{*}{$\mathrm{S} 1$} & AGGCAGTTGAGACGAACATTCCTAAGTCTGAAATTIATCACCCGCCATAGT \\
\hline & AGACGTATCACC \\
\hline \multirow{2}{*}{$\mathrm{S} 2$} & CTTGCTACACGATTCAGACTTAGGAATGTTCGACATGCGAGGGTCCAATAC \\
\hline & CGACGATTACAG \\
\hline \multirow{2}{*}{ S3 } & GGTGATAAAACGTGTAGCAAGCTGTAATCGACGGGAAGAGCATGCCCATC \\
\hline & CACTACTATGGCG \\
\hline \multirow{2}{*}{ S4 } & СCTCGCATGACTCAACTGCCTGGTGATACGAGGATGGGCATGCTCTTCCCG \\
\hline & ACGGTATTGGAC \\
\hline \multicolumn{2}{|c|}{ DNA origami staples } \\
\hline t1rog & AGGGTTGATATAAGTATAGCCCGGAATAGGTG \\
\hline t1r2e & TAAGCGTCGGTAATAAGTTTAACCCGTCGAG \\
\hline $\operatorname{t} 1 \mathrm{r} 2 \mathrm{f}$ & AGTGTACTATACATGGCTITGATCTTICCAG \\
\hline t1r4e & AACCAGAGACCCTCAGAACCGCCACGTTCCAG \\
\hline t1ruf & GAGCCGCCCCACCACCGGAACCGCTGCGCCGA \\
\hline tlir6e & GACTTACGTAAAGGTCGCAACATACCGTCACC \\
\hline t1r6f & AATCACCACCATTTGGGAATTAGACCAACCTA \\
\hline t1r8e & ТTATTACGTAAAGGTCGCAACATACCGTCACC \\
\hline t1r8f & TACATACACAGTATGTTAGCAAACTGTACAGA \\
\hline t1r10e & TGAACAAAGATAACCCACAAGAATAAGACTCC \\
\hline t1r10f & ATCAGAGAGTCAGAGGGTAATTGAACCAGTCA \\
\hline t1r12e & TATTTGGACGCTAACGAGCGTCTGAACACCC \\
\hline $\operatorname{t1r} 12 f$ & TCTTACCAACCCAGCTACAATTTAAAGAAGT \\
\hline t1r14e & ATCGGGCTGACCAAGTACCGCACTCTTAGTTGC \\
\hline $\operatorname{t1r} 14 f$ & GGTATTAATCTTTCCTTATCATTCATATCGCG \\
\hline t1r16e & САTATTATTCGAGCCAGTAATAAATCAATA \\
\hline $\operatorname{t} 1 \mathrm{r} 16 \mathrm{f}$ & AGAGGCATACAACGCCAACATGTATCTGCGAA \\
\hline t1r18e & ACAAAGAAAATTTCATCTTCTGACAGAATCGC \\
\hline $\operatorname{t1r18f}$ & ПTTAGTTCGCGAGAAAACTTITITATGACC \\
\hline t1r20e & AAATCAATCGTCGCTATTAATTAAATCGCAAG \\
\hline t1r20f & CTGTAAATATATGTGAGTGAATAAAAAGGCTA \\
\hline
\end{tabular}




\begin{tabular}{|c|c|}
\hline t1r22e & TTAAACGTTCGGGAGAAACAATAACAGTACAT \\
\hline $\operatorname{tlr} 22 f$ & CTITIACACAGATGAATATACAGTGCCATCAA \\
\hline tlr24e & TTATTAATGAACAAAGAAACCACCTITCAGG \\
\hline $\operatorname{t} 1 \mathrm{r} 24 \mathrm{f}$ & ATITGCGTTAAAAGTTGAGTACCGGCACC \\
\hline t1r26e & CTAAAGCAAATCAATATCTGGTCACCCGAACG \\
\hline $\operatorname{t} 1 \mathrm{r} 26 f$ & AAACCСTCTCACCTTGCTGAACCTAGAGGATC \\
\hline t1r28e & CTAAAAGCAAATCAATATCTGGTCACCCGAACG \\
\hline t1r28f & GCGTAAGAAGATAGAACCCTTCTGAACGCGCG \\
\hline t1r30e & GTTGTAGCCCTGAGTAGAAGAACTACTTCTG \\
\hline t1r30f & ATCACTTGAATACTTCTTGATTAGTTGTTCC \\
\hline t1r32h & TACAGGGCGCGTACTATGGTTGCTAATTAACC \\
\hline t3rog & TGCTCAGTACCAGGCGGATAAGTGGGGGTCAG \\
\hline t3r2e & GGAAAGCGGTAACAGTGCCCGTATCGGGGTT \\
\hline t3r2f & TGCCTTGACAGTCTCTGAATTACCCCTCAGA \\
\hline t3r4e & GTTGCCACCTCAGAGCCGCCACCGCCAGAAT \\
\hline t3r4f & GCCACCACTCTIITCATAATCAAATAGCAAGG \\
\hline t3r6e & TTATTCATGTCACCAATGAAACCATTATTAGC \\
\hline t3r6f & CCGGAAACTAAAGGTGAATTATCATAAAAGAA \\
\hline t3r8e & ATACCCAAACACCACGGAATAAGTGACGGAAA \\
\hline t3r8f & ACGCAAAGAAGAACTGGCATGATTTGAGTTAA \\
\hline t3r10e & GCGCATTAATAAGAGCAAGAAACAATAACGGA \\
\hline t3r10f & GCCCAATAGACGGGAGAATTAACTTTCCAGAG \\
\hline t3r12e & AGGTITGGCCAGTTACAAAATAAACAGGGAA \\
\hline t3r12f & ССTAATTAAAGCTTAAATCAAGAATCGAGAA \\
\hline t3r14e & СTAATTACCGTIITATITCATCTTGCGGG \\
\hline$t 3 r 14 f$ & CAAGCAAGCGAGCATGTAGAAACCAGAGAATA \\
\hline t3r16e & ACGCTCAACGACAAAAGGTAAAGTATCCCATC \\
\hline t3r16f & TAAAGTACCAGTAGGGCTTAATTGCTAAATTा \\
\hline t3r18e & TATGTAAAGAAATACCGACCGTGTTAAAGCCA \\
\hline t3r18f & AATGGTITGCTGATGCAAATCCATITCCCT \\
\hline t3r20e & TTGAATTATTGAAAACATAGCGATTATAACTA \\
\hline t3r20f & TAGAATCCCCTIIITAATGGAAACGGATTCG \\
\hline t3r22e & ACAGAAATCTTTGAATACCAAGTTAATTTCAT \\
\hline$t 3 r 22 f$ & СCTGATTGAAAGAAATTGCGTAGAAGAAGGAG \\
\hline & CGACAACTTCATCATATTCCTGATCACGTAAA \\
\hline
\end{tabular}




\begin{tabular}{|c|c|}
\hline$t 3 r 24 f$ & CGGAATTACGTATTAAATCCTITGGTTGGCAA \\
\hline t3r26e & GCCACGCTTTGAAAGGAATTGAGGAAACAATT \\
\hline$t 3 r 26 f$ & ATCAACAGGAGAGCCAGCAGCAAAATATITT \\
\hline t3r28e & GTCACACGATTAGTCTTTAATGCGGCAACAGT \\
\hline t3r28f & GAATGGCTACCAGTAATAAAAGGGCAAACTAT \\
\hline t3r30e & GTAAAAGACTGGTAATATCCAGAAATTCACCA \\
\hline t3r30f & CGGCCTTGGTCTGTCCATCACGCATTGACGAG \\
\hline t3r32h & CACGTATAACGTGCTITCCTCGTTGCCACCGA \\
\hline t5rog & CCTCAAGAGAAGGATTAGGATTAGAAACAGTT \\
\hline t5r2e & ACAAACAACTGCCTATTCGGAACCTGAGACT \\
\hline t5r $2 f$ & AATGCCCCATAAATCCTCATTAAAAGAACCAC \\
\hline t5r4e & TCGGCATTCCGCCGCCAGCATTGATGATATTC \\
\hline t5r4f & CACCAGAGTTCGGTCATAGCCCCCTCGATAGC \\
\hline t5r6e & ATTGAGGGAATCAGTAGCGACAGACGTITTCA \\
\hline t5r6f & AGCACCGTAGGGAAGGTAAATATTTATITG \\
\hline t5r8e & GAAGGAAAAATAGAAAATTCATATTCAACCG \\
\hline t5r8f & TCACA ATCCC GAGGA AACGC AATAA TGAAATA \\
\hline t5r10e & СTTACAGTATCTTACCGAAGCCCAGTTACCA \\
\hline t5r10f & GCAATAGCAGAGAATAACATAAAAACAGCCAT \\
\hline $\mathrm{t} 5 \mathrm{r} 12 \mathrm{e}$ & GAGGCGTTTCCCAATCCAAATAAGATAGCAGC \\
\hline$t 5 r 12 f$ & АTTATTATTAGCGAACCTCCCGACGTAGGAA \\
\hline $\mathrm{t} 5 \mathrm{r} 14 \mathrm{e}$ & TAAGTCCTGCGCCCAATAGCAAGCAAGAACGC \\
\hline$t 5 r 14 f$ & TCATTACCGAACAAGAAAAATAATAATTCTGT \\
\hline$t 5 r 16 f$ & CCAGACGACAAATTCTTACCAGTAGATAAATA \\
\hline t5r18e & TAACCTCCAATAAGAATAAACACCTATCATAT \\
\hline t5r18f & AGGCGTTAGGCTTAGGTTGGGTTAAGCTTAGA \\
\hline $\mathrm{t} 5 \mathrm{r} 20 \mathrm{e}$ & AAAACAAACTGAGAAGAGTCAATATACCTIT \\
\hline t5r20f & ТTAAGACGATTAATTACATTAACACAAAATC \\
\hline t5r22e & АACCTACCGCGAATTATTCATTСССATCAAG \\
\hline$t 5 r 22 f$ & GCGCAGAGATATCAAAATTATTTGTATCAGAT \\
\hline $\mathrm{t} 5 \mathrm{r} 24 \mathrm{e}$ & GGATTAGTTCATCAATATAATCCAGGGTTAG \\
\hline $\mathrm{t} 5 \mathrm{r} 24 \mathrm{f}$ & GATGGCAAAAGTATTAGACTTIACAAGGTTAT \\
\hline t5r26e & AGGCGGTCTCTTAGGAGCACTAAACATTTGA \\
\hline $\mathrm{t} 5 \mathrm{r} 26 \mathrm{f}$ & СTAAAATAAGTATTAACACCGCCTCGAACTGA \\
\hline & GAAATGGAAAACATCGCCATTAAACAGAGGTG \\
\hline
\end{tabular}


t5r28f

t5r30e

t5r30f

t5r32h

t-1rog

t-1r2e

t-1r2f

t-1r4e

t-1r4f

t-1r6e

t-1r6f

t-1r8e

t-1r8f

t-1r10e

t-1r10f

t-1r12e

t-1r12f

t-1r14e

t-1r14f

t-1r16e

t-1r16f

t-1r18e

t-1r18f

t-1r20e

t-1r20f

t-1r22e

t-1r22f

t-1r24e

t-1r24f

t-1r26e

t-1r26f

t-1r28e

t-1r28f

t-1r30e

t-1r30f
TAGCCCTATTATTAACATGGCAGCAATATTA

AGAAGTGTCATTGCAACAGGAAAAAATCGTCT

CCGCCAGCTITTATAATCAGTGAGAGAATCAG

AGCGGGAGCTAAACAGGAGGCCGAGAATCCTG

TATCACCGTACTCAGGAGGTTIAGATAGTTAG

ACGTTAGTTCTAAAGTTTGTCGTGATACAGG

CGTAACGAAAATGAATTTCTGTAGTGAATT

CAATGACAGCTTGATACCGATAGTCTCCCTCA

CTTAAACAACAACCATCGCCCACGCGGGTAAA

AAACGAAATGCCACTACGAAGGCAGCCAGCAA

ATACGTAAGAGGCAAAAGAATACACTGACCAA

CCAGGCGCGAGGACAGATGAACGGGTAGAAAA

CTITGAAAATAGGCTGGCTGACCTACCTTATG

GGACGTTGAGAACTGGCTCATTATGCGCTAAT

CGATTTIAGGAAGAAAAATCTACGGATAAAAA

TाTGCCAGGCGAGAGGCTITTGCAATCCTGAA

CCAAAATAAGGGGGTAATAGTAAAAAAAGATT

TITAATTGCCCGAAAGACTTCAACAAGAACG

AAGAGGAACGAGCTTCAAAGCGAAAGTTCAT

CGAGTAGAACAGTTGATTCCCAATATTTAGGC

TCCATATATTAATTTGACCATTAAGCATAAA

CTGTAATAGGTTGTACCAAAAACACAAATATA

GCTAAATCCTITTGCGGGAGAAGCCCGGAGAG

TCAGGTCATTITTGAGAGATCTACCCTTGCTT

GGTAGCTATTGCCTGAGAGTCTGGTTAAATCA

AAATAATTITTAACCAATAGGAACAACAGTAC

GCTCATTTCGCGTCTGGCCTTCCTGGCCTCAG

GCTTCTGGCACTCCAGCCAGCTTTACATTATC

GAAGATCGTGCCGGAAACCAGGCAGTGCCAAG

CCCGGGTACCTGCAGGTCGACTCTCAAATATC

CTTGCATGCCGAGCTCGAATTCGTCCTGTCGT

GGGAGAGGCATTAATGAATCGGCCACCTGAAA

GCCAGCTGCGGTTTGCGTATTGGGAATCAAAA

AGTTGGACGAGATAGGGTTGAGTGTAATAAC

GAATAGCCACAAGAGTCCACTATTAAGCCGGC 


\begin{tabular}{|c|c|}
\hline$t-1 r 32 h$ & GAACGTGGCGAGAAAGGAAGGGAATGCGCCGC \\
\hline t-3r0g & CCCTCAGAACCGCCACCCTCAGAAACAACGCC \\
\hline$t-3 r 2 e$ & TGCTAAACTCCACAGACAGCCCTCTACCGCCA \\
\hline$t-3 r 2 f$ & TGTAGCATAACTTTCAACAGTTTCTAATTGTA \\
\hline$t-3 r 4 e$ & ATATATTCTCAGCTTGCTITCGAGTGGGATT \\
\hline$t-3 r 4 f$ & TCGGTTAAGGTCGCTGAGGCTTGCAAAGACTT \\
\hline t-3r6e & СTCATCTTGGAAGTTTCCATTAAACATAACCG \\
\hline & TाTCATGATGACCCCCAGCGATTAAGGCGCAG \\
\hline$t-3 r 8 e$ & AGTAATCTTCATAAGGGAACCGAACTAAAACA \\
\hline$t-3 r 8 f$ & ACGGTCAATGACAAGAACCGGATATGGTTAA \\
\hline$t-3 r 10 e$ & ACGAACTATTAATCATTGTGAATTTCATCAAG \\
\hline$t-3 r 10 f$ & ПТТАACTACGGAACAACATTATTAACACTAT \\
\hline $\mathrm{t}-3 \mathrm{r} 12 \mathrm{e}$ & ACTGGATATCGTITACCAGACGACTTAATAAA \\
\hline & CATAACCCGCGTCCAATACTGCGGTATTATAG \\
\hline$t-3 r 14 e$ & GAAGCAAAAAAGCGGATTGCATCAATGTTAAG \\
\hline$t-3 r 14 f$ & TCAGAAGCCTCCAACAGGTCAGGATTTAAATA \\
\hline$t-3 r 16 f$ & TGCAACTAGGTCAATAACCTGTITAGAATTAG \\
\hline & CAACGCAAAGCAATAAAGCCTCAGGATACATT \\
\hline$t-3 r 18 f$ & CAAAATTAGGATAAAAATITTAGGATATTCA \\
\hline$t-3 r 20 e$ & AGAGAATCAGCTGATAAATTAATGCTTTATT \\
\hline$t-3 r 20 f$ & ACCGTTCTGATGAACGGTAATCGTAATATIT \\
\hline$t-3 r 22 e$ & CTITCATCTCGCATTAAATIITGAGCAAACA \\
\hline$t-3 r 22 f$ & GTTAAAATAACATTAAATGTGAGCATCTGCCA \\
\hline$t-3 r 24 e$ & TTCGCCATGGACGACGACAGTATCGTAGCCAG \\
\hline$t-3 r 24 f$ & GTTGAGGTCAGGCTGCGCAACTGTTCCCAGT \\
\hline$t-3 r 26 e$ & TCATAGCTTGTAAAACGACGGCCAAAGCGCCA \\
\hline$t-3 r 26 f$ & CACGACGTGTTTCCTGTGTGAAATTTGCGCTC \\
\hline$t-3 r 28 e$ & TGGTIITCTITCCAGTCGGGAAAAATCATGG \\
\hline$t-3 r 28 f$ & ACTGCCCGCTITCACCAGTGAGATGGTGGTT \\
\hline $3 \mathrm{r} 30 \mathrm{e}$ & TGGACTCCGGCAAAATCCCTTATACGCCAGGG \\
\hline$t-3 r 30 f$ & CCGAAATCAACGTCAAAGGGCGAAAAGGGAGC \\
\hline$t-3 r 32 h$ & CCCCGATTTAGAGCTTGACGGGGAAAAGAACG \\
\hline & CTCAGAGCCACCACCCTCATITICCGTAACAC \\
\hline & GAGAATAGGTCACCAGTACAAACTCCGCCACC \\
\hline & TGAGTTTCAAAGGAACAACTAAAGATCTCCAA \\
\hline
\end{tabular}




\begin{tabular}{|c|c|}
\hline $\mathrm{t}-5 \mathrm{r} 4 \mathrm{e}$ & AAAGGCCGCTCCAAAAGGAGCCTTAGCGGAGT \\
\hline$t-5 r 4 f$ & AAAAAAGGCTITTGCGGGATCGTCGGGTAGCA \\
\hline$t-5 r 6 e$ & GCGAAACAAGAGGCTTTGAGGACTAGGGAGTT \\
\hline$t-5 r 6 f$ & ACGGCTACAAGTACAACGGAGATTCGCGACCT \\
\hline t-5r8e & CCAAATCATTACTTAGCCGGAACGTACCAAGC \\
\hline$t-5 r 8 f$ & GCTCCATGACGTAACAAAGCTGCTACACCAGA \\
\hline$t-5 r 10 e$ & AAAGATTCTAAATTGGGCTTGAGATTCATTAC \\
\hline$t-5 r 10 f$ & ACGAGTAGATCAGTTGAGATTAGCGCCAAAA \\
\hline$t-5 r 12 e$ & TAAATATTGAGGCATAGTAAGAGCACAGGTAG \\
\hline$t-5 r 12 f$ & GGAATTACCATTGAATCCCCCTCACCATAAAT \\
\hline$t-5 r 14 e$ & TACCTTAAGGTCTTTACCCTGACAATCGTCA \\
\hline$t-5 r 14 f$ & САAAAATCATTGCTCCTITTGATAATTGCTGA \\
\hline$t-5 r 16 e$ & TाTCATTCTGTAGCTCAACATGTITAGAGAG \\
\hline$t-5 r 16 f$ & ATATAATGGGGGCGCGAGCTGAAATTAACATC \\
\hline$t-5 r 18 e$ & TATATITCATACAGGCAAGGCAAAGCTATAT \\
\hline$t-5 r 18 f$ & CAATAAATAAATGCAATGCCTGAGAAGGCCGG \\
\hline$t-5 r 20 e$ & CATGTCAAAAATCACCATCAATATAACCCTCA \\
\hline$t-5 r 20 f$ & AGACAGTCTCATATGTACCCCGGTITGTATAA \\
\hline$t-5 r 22 e$ & ACCCGTCGTTAAATTGTAAACGTTAAAACTAG \\
\hline$t-5 r 22 f$ & GCAAATATGATTCTCCGTGGGAACCGTTGGTG \\
\hline$t-5 r 24 e$ & GGCGATCGCGCATCGTAACCGTGCGAGTAACA \\
\hline$t-5 r 24 f$ & TAGATGGGGTGCGGGCCTCTTCGCGCAAGGCG \\
\hline$t-5 r 26 e$ & GCTCACAAGGGTAACGCCAGGGTITGGGAAG \\
\hline$t-5 r 26 f$ & ATTAAGTITTCCACACAACATACGCCTAATGA \\
\hline$t-5 r 28 e$ & AGCTGATTACTCACATTAATTGCGTGTTATCC \\
\hline$t-5 r 28 f$ & GTGAGCTAGCCCTTCACCGCCTGGGGTTGCC \\
\hline$t-5 r 30 e$ & TATCAGGGCGAAAATCCTGTTTGACGGGCAAC \\
\hline$t-5 r 30 f$ & CCAGCAGGCGATGGCCCACTACGTGAGGTGCC \\
\hline$t-5 r 32 h$ & GTAAAGCACTAAATCGGAACCCTAAAACCGTC \\
\hline
\end{tabular}


Table S3. HPLC analysis and M ALDI-TOF characterization of modified staples required for DNA Td and DNA origami assembly. Calculated (calc) and experimental (exp) molecular weights are compiled for comparison.

\begin{tabular}{|c|c|c|c|c|c|}
\hline Sample & it (min) & MW calc/ exp & Sample & rt (min) & MW calc/ exp \\
\hline \multicolumn{6}{|c|}{ DNA Tetrahedron } \\
\hline S1-FdU 10 & $\mathrm{a}_{5.4}$ & $22423.1 / 22464.0$ & Chol-S4a & 14.0 & $6591.8 / 6593.7$ \\
\hline Chol-S2a & 13.6 & $6645.8 / 6646.9$ & Chol-S4b & 13.9 & $13924.5 / 13909.6$ \\
\hline Chol-S2b-FdU 10 & 13.9 & $16912.1 / 16978.4$ & Fluorescein-S5 & 5.3 & $6855.8 / 6872.9$ \\
\hline Chol-S3a & 13.9 & $6807.9 / 6810.3$ & Cy3-S5 & 7.5 & $6399.4 / 6406.3$ \\
\hline Chol-S3b & 13.7 & $13831.4 / 13820.7$ & & & \\
\hline \multicolumn{6}{|l|}{ DNA origami } \\
\hline $\mathrm{FdU}_{10}$ & $a_{5.0}$ & $3020.0 / 3018.1$ & & & \\
\hline$t-5 r 4 e-F d U_{13}$ & ${ }^{\mathrm{a}} 6.1$ & $13897.5 / 13904.5$ & Chol-t-3r18f & 12.6 & $11378.2 / 11380.3$ \\
\hline$t-3 r 2 f-F d U_{14}$ & ${ }^{\mathrm{a}} 6.3$ & $14100.6 / 14119.7$ & Chol-t5r14f & 13.0 & $11308.2 / 11307.2$ \\
\hline t3r4e-FdU 14 & ${ }^{\mathrm{a}} 6.1$ & $14028.5 / 14034.5$ & Chol-t5r18f & 12.7 & $11496.9 / 11495.2$ \\
\hline t5r2f- FdU & ${ }^{\mathrm{a}} 6.1$ & $14011.6 / 14011.7$ & Chol-t-1r22f & 13.2 & $11216.7 / 11220.9$ \\
\hline$t-3 r 8 e-F d U_{10}$ & ${ }^{\mathrm{a}} 5,5$ & $12923.0 / 12933.4$ & Chol-t1r22e & 12.9 & $11370.9 / 11365.3$ \\
\hline t3r6f-FdU 10 & ${ }^{\mathrm{a}} 5.4$ & $12987.1 / 12983.7$ & Chol-t-1r30f & 13.0 & $11317.8 / 11314.0$ \\
\hline Chol-t-3r14f & 12.7 & $11326.2 / 11328.7$ & Chol-tlr30e & 12.9 & $11369.8 / 11367.5$ \\
\hline
\end{tabular}

$\mathrm{FdU}_{\mathrm{n}} \mathrm{n}$ in subscript stands for the number of FdU monomers, Chol for a cholesterol moiety and Cy3 for Cyanine $540 .{ }^{a}$ The HPLC gradient was increased from 0-50\% acetonitrile in $20 \mathrm{~min}$; the remaining samples were analyzed following the HPLC gradient increased from; $0-15 \%$ over 5 min, followed by $15-40 \%$ over 1 min and $40-85 \%$ over 9 min. 
Table S4. Averaged hydrodynamic size determined for Td and DNA origami through dynamic light scattering (DLS). The sizes of unmodified Td (Td) and DNA origami (Origami-N) are listed and compared with $\mathrm{FdU}_{\mathrm{n}}$ - and cholesterol-modified nanostructures, Td-1F, Td-1F-2C, Td-1F-3C, Td-1F-4C, Td-2F-3C, Origami-4F, Origami-6F, Origami-4F-4C and Origami-6F-8C. Data was measured in triplicate. The polydispersity index (PdI) and respective standard deviation (SDPdl) are also reported.

\begin{tabular}{lcccc}
\hline Sample & Hydrodynamic size $\mathbf{( d ~} \mathbf{~ n m})$ & SD & Pdl & SD-Pdl \\
\hline DNA Tetrahedron & & & & \\
\hline Td & 24.5 & \pm 5.8 & 0.44 & \pm 0.01 \\
Td-1F & 26.4 & \pm 4.4 & 0.45 & \pm 0.07 \\
Td-1F-2C & 94.3 & \pm 4.8 & 0.38 & \pm 0.02 \\
Td-1F-3C & 100.5 & \pm 4.8 & 0.39 & \pm 0.19 \\
Td-1F-4C & 187.7 & \pm 34.7 & 0.27 & \pm 0.11 \\
Td-2F-3C & 76.4 & \pm 14.8 & 0.43 & \pm 0.17 \\
\hline DNA origami & & & & \\
\hline Origami-N & 124.3 & \pm 3.8 & 0.26 & \pm 0.09 \\
Origami-4F & 133.5 & \pm 6.47 & 0.39 & \pm 0.06 \\
Origami-6F & 117.7 & \pm 2.2 & 0.23 & \pm 0.01 \\
Origami-4F-4C & 131.2 & \pm 3.2 & 0.34 & \pm 0.05 \\
Origami-6F-8C & 141.2 & \pm 6.2 & 0.33 & \pm 0.05 \\
\hline
\end{tabular}


Table S5. This table summarizes the concentration of DNA nanoscaffolds and their respective total number of equivalents of $\mathrm{FdU}$. The control $\mathrm{FdU}_{10}$ is also listed.

\begin{tabular}{cccc}
\hline Sample & $\begin{array}{c}\text { Number of FdU } \\
\text { units }\end{array}$ & $\begin{array}{c}\text { Molar concentration of } \\
\text { DNA nanoscaffolds }(\boldsymbol{\mu M})\end{array}$ & $\begin{array}{c}\text { Total number of FdU } \\
\text { equivalents }(\boldsymbol{\mu M})\end{array}$ \\
\hline DNA Tetrahedron & & & 5 \\
\hline Control FdU 10 & 10 & 0.5 & 5 \\
Td-1F & 10 & 0.5 & 5 \\
Td-1F-2C & 10 & 0.5 & 5 \\
Td-1F-3C & 10 & 0.5 & 5 \\
Td-1F-4C & 10 & 0.5 & 5 \\
Td-2F-3C & 20 & 0.25 & \\
\hline DNA origami & & & 0.110 \\
\hline Origami-4F & 55 & 0.002 & 0.150 \\
Origami-6F & 75 & 0.002 & 0.110 \\
Origami-4F-4C & 55 & 0.002 & 0.150 \\
Origami-6F-8C & 75 & 0.002 & \\
\hline
\end{tabular}




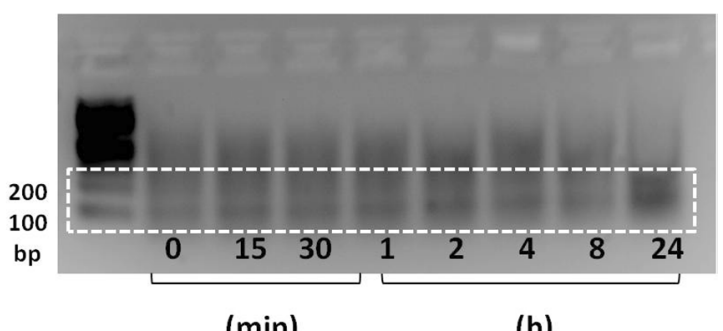

(min)

(h)

Figure S1. Long-term stability of the DNA Td in cell culture medium measured in $2.5 \%$ agarose gel electrophoresis. Each lane represents the migration of standard Td after different times of incubation with DMEM plus $10 \%$ FBS, at $37^{\circ} \mathrm{C}$, (lane 2) $t=0$, (lane 3) $t=15 \mathrm{~min}$, (lane 4) $t=30$ min, (lane 5) $t=1 h$, (lane 6) $t=2 h$, (lane 7 ) $t=4 h$, (lane 8 ) $t=8 h$ and (lane 9) $t=24 h$. Lane (1) shows the migration of the DNA ladder with $100 \mathrm{bp}$.

A

\section{$\begin{array}{llllllllllllll}1 & 2 & 3 & 4 & 5 & 6 & 7 & 8 & 9 & 9 & 10 & 12 & 13\end{array}$}

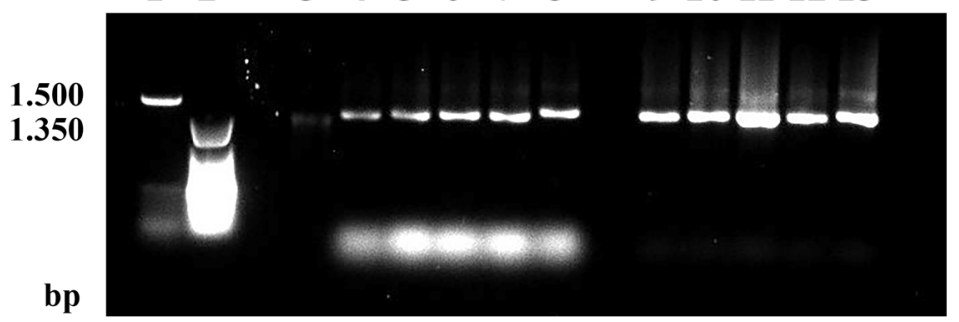

B

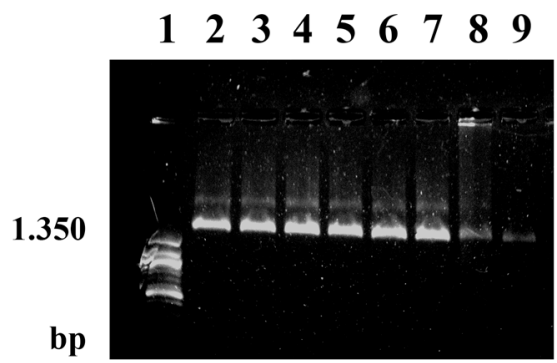

Figure S2. Gel electrophoresis analysis and stability of DNA origami, 1\% agarose gel. A, Shows the formation and purification of the different DNA origami prepared. (1) $10 \mathrm{bp} \mathrm{ladder,} \mathrm{(2)} 50$ bp ladder, (3) M13 scaffold alone, (4-8) DNA origami formation (9-13) DNA origami after purification, $(4,9)$ DNA origami, $(5,10)$ DNA origami 4-F, $(6,11)$ DNA origami-4F-4C, $(7,12)$ DNA origami-6F, $(8,13)$ DNA origami-6-F-8C. B, Shows the stability of the DNA origami over time in DMEM plus $10 \%$ FBS at $37^{\circ} \mathrm{C}$ (1) 50 bp ladder, (2) $t=0$, (3) $t=15$ min, (4) $t=30$ min, (5) $t=60 \min ,(6) t=120 \min ,(7) t=240 \min ,(8) t=480 \min$ and (9) $t=24 \mathrm{~h}$. 
A
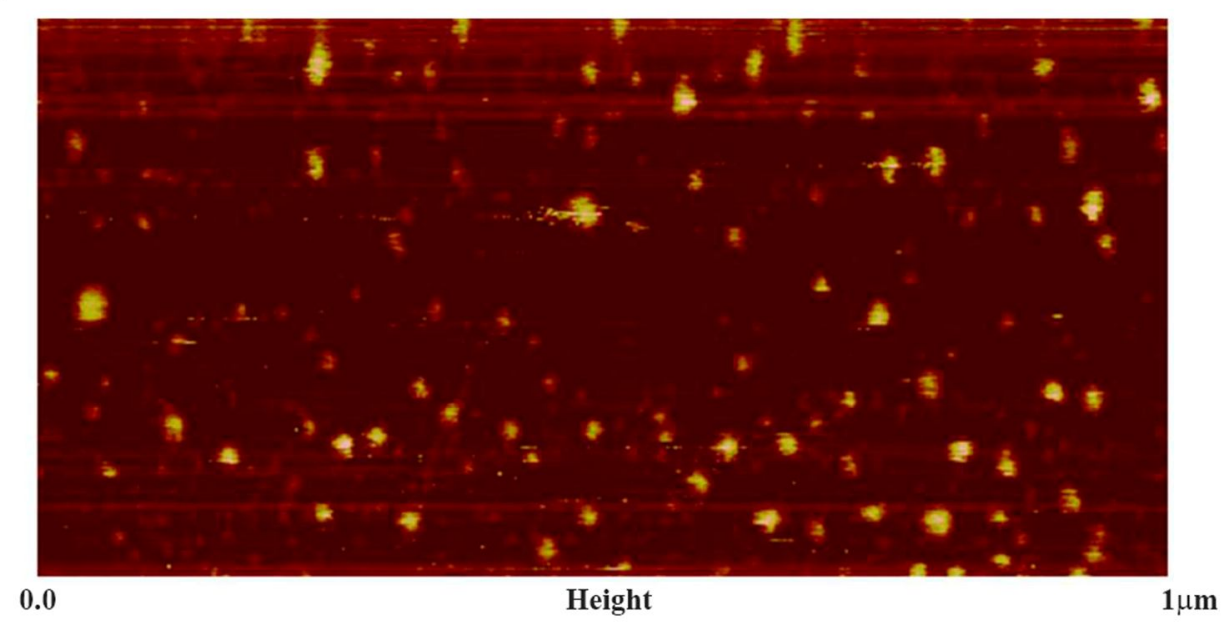

B

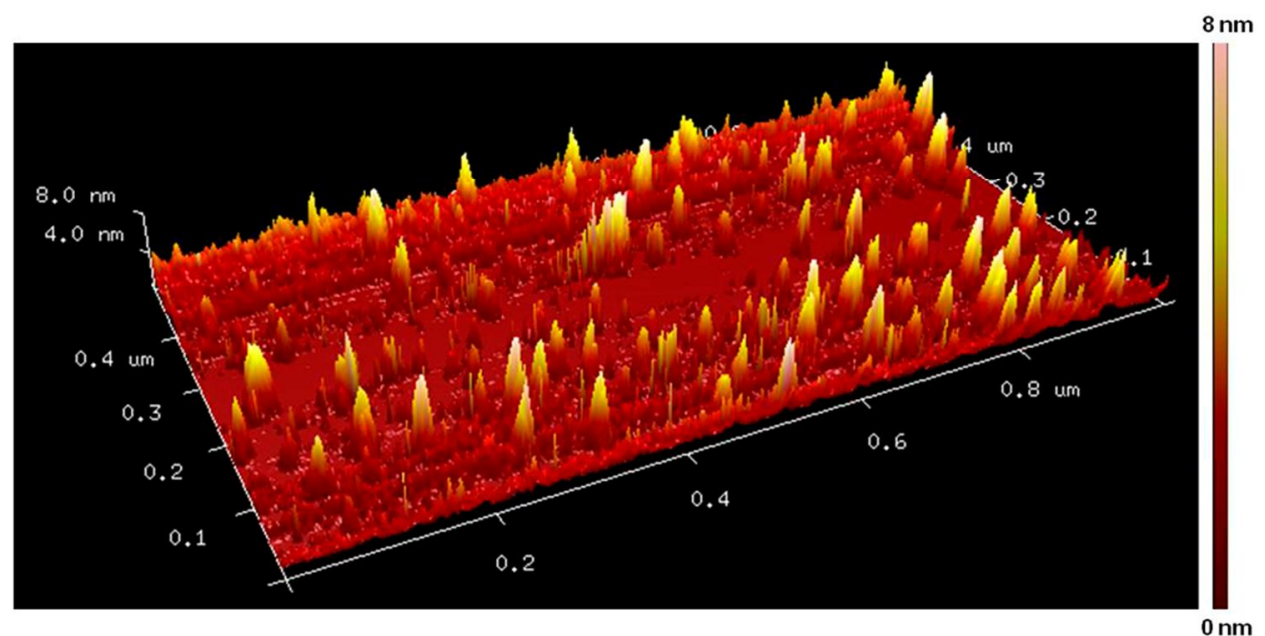

Figure S3: Additional AFM images of DNA Td. A, AFM image showing DNA tetrahedron deposited on mica surface. B, 3D representations of the DNA Td deposited in mica. Color bar indicates the height of the nanostructures. 
A

B

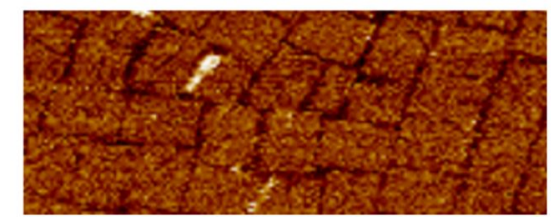

0.0

Height

$655 \mathrm{~nm}$

0.0

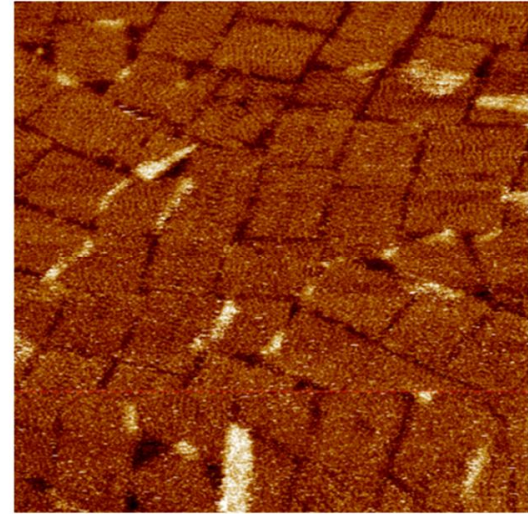

.0 Height

$655 \mathrm{~nm}$

Figure S4. AFM images of the unmodified DNA origami. Image size $328 \mathrm{~nm} \times 656 \mathrm{~nm}$ and 656 $\mathrm{nm} \times 656 \mathrm{~nm}$ Image height: $-2.0 \mathrm{~nm}$ to $2.7 \mathrm{~nm}$.
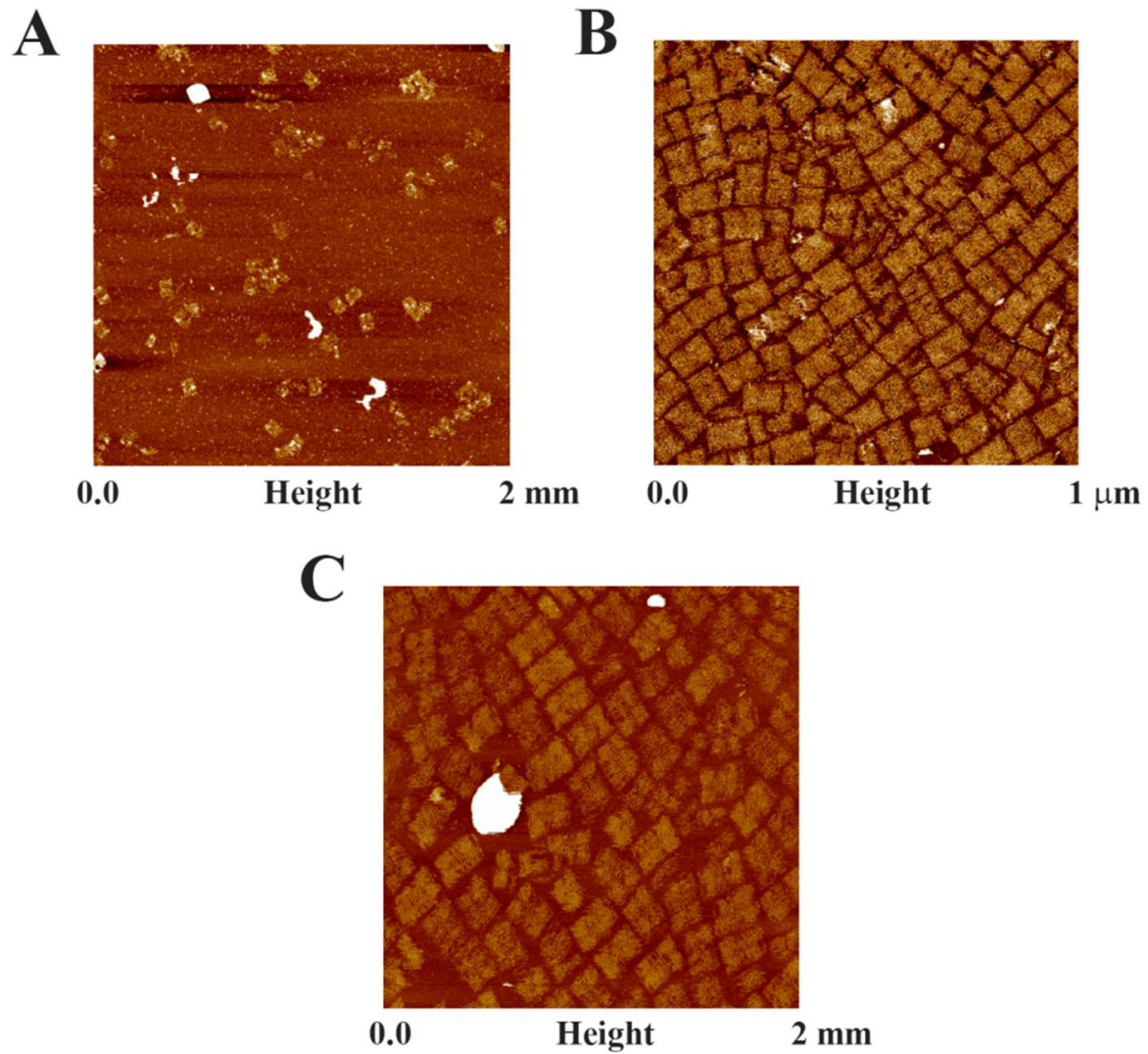

Figure S5. AFM images of the DNA origami containing A, 4 FdU staples, B, 4 FdU-4C and C, 6 FdU-8C staple displaced in different positions. DNA origami were formed correctly, showing that the introduction of the modified tiles did not affect its assembly. 
A

HTB-38

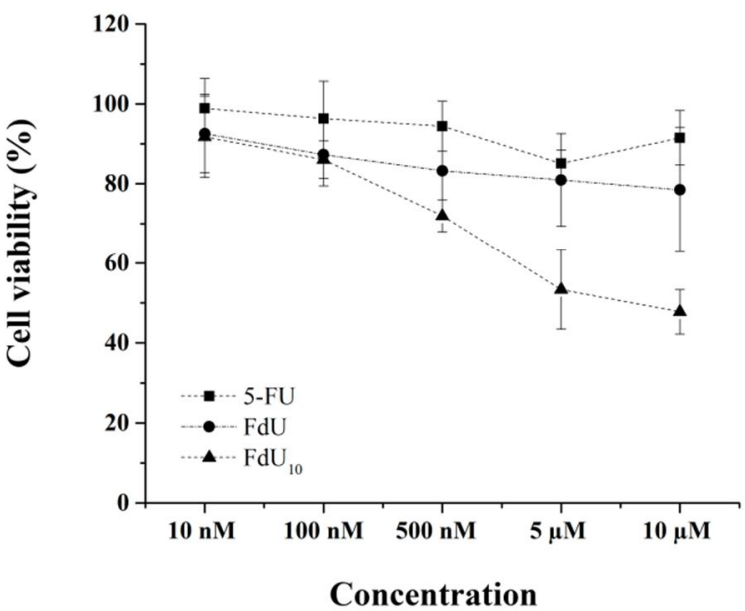

B HCC2998

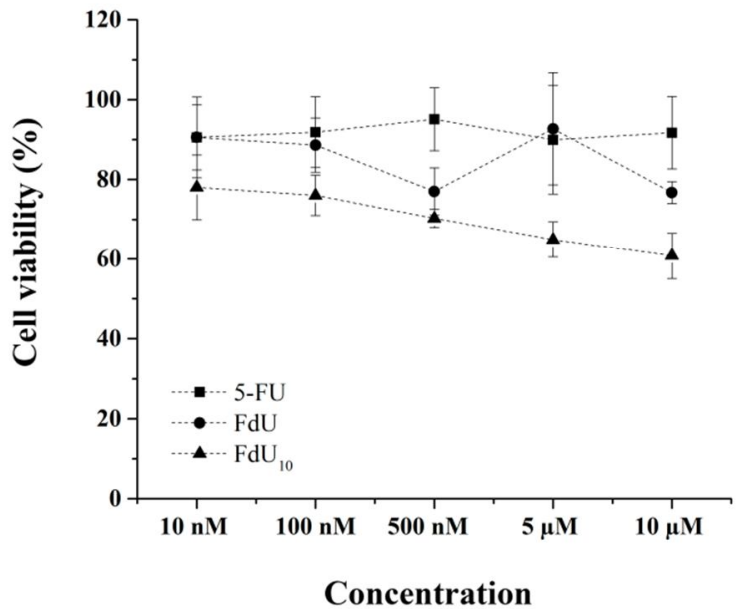

Figure S6. 5-fluoro-uracil (5-FU), 5-fluoro-2'-deoxyuridine (FdU) and polymeric 5-fluoro-2'deoxyuridine $\left(\mathrm{FdU}_{10}\right)$ cytotoxic activity measured through $\mathrm{MT}$ assay in, $\mathbf{A}, \mathrm{HTB}-38$ and $\mathbf{B}$, HCC2998 cells. The values obtained for 5-FU, FdU and FdU $_{10}$ are shown as fill squares, circles and triangles, respectively. All the data are normalized to DMSO and PBS both used as control for drugs and polymeric form, respectively. The concentration assayed ranges from 10 nanomolar $(\mathrm{nM})$ to 10 micromolar $(\mu \mathrm{M})$. Data represent the mean values and standard deviation measured in duplicate for three independent experiments. 
A

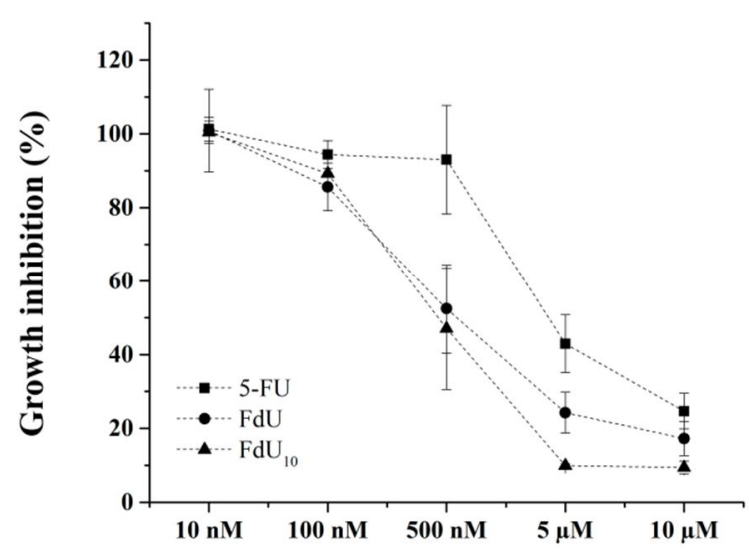

Concentration
B

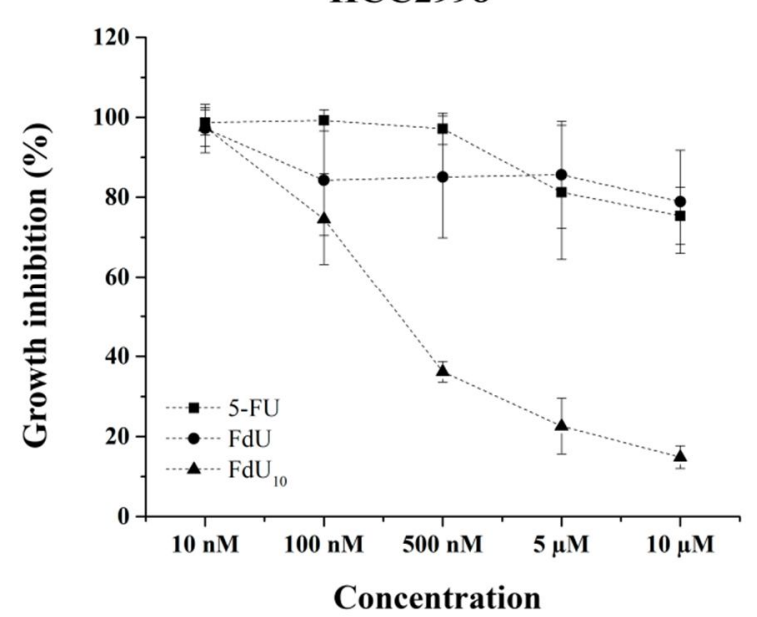

Figure S7. Growth inhibition assays. 5-fluoro-uracil (5-FU), 5-fluoro-2'-deoxyuridine (FdU) and polymeric 5-fluoro-2'-deoxyuridine $\left(\mathrm{FdU}_{10}\right)$ were assayed in two different types of colorectal cancer cell A, HTB-38 and B, HCC2998. The values obtained for 5-FU, FdU and FdU 10 are shown as fill square, circles and triangles, respectively. All the data are normalized to DM SO and PBS both used as control for drugs and polymeric form, respectively. The concentration assayed range from 10 nanomolar $(\mathrm{nM})$ to 10 micromolar $(\mu \mathrm{M})$. Data represent the mean values and standard deviation measured in duplicate for three independent experiments.

\section{References}

1. Gupta KC, Kumar P, Bhatia D and Sharma AK, Nucleosides Nucleotides 1995, 14, 829.

2. M. J. Damha, P. A. Giannaris and S. V. Zabarylo, Nucleic Acids Res, 1990, 18, 3813-3821. 